\title{
The Role of Topographically Induced Vortices in Tropical Cyclone Formation over the Indian Ocean 0
}

\author{
Caitlin M. Fine, Richard H. Johnson, Paul E. Ciesielski, and Richard K. TAFT \\ Department of Atmospheric Science, Colorado State University, Fort Collins, Colorado
}

(Manuscript received 11 March 2016, in final form 25 July 2016)

\begin{abstract}
The role of Sumatra and adjacent topographic features in tropical cyclone (TC) formation over the Indian Ocean (IO) is investigated. Sumatra, as well as the Malay Peninsula and Java, have mountainous terrain that partially blocks low-level flow under typical environmental stratification. For easterly low-level flow, these terrain features often produce lee vortices, some of which subsequently shed and move westward from the northern and southern tips of Sumatra and thence downstream over the IO. Since Sumatra straddles the equator, extending in a northwest-southeast direction from approximately $6^{\circ} \mathrm{N}$ to $6^{\circ} \mathrm{S}$, the lee vortices, while counter-rotating, are both cyclonic. Hence, they can serve as initial disturbances that eventually contribute to TC formation over the IO. In addition, low-level, equatorial westerly flow impinging on Sumatra is also typically blocked and diverges, at times contributing to cyclonic circulations over the IO, primarily near the southern end of the island.

Data from two recent tropical campaigns, the 2008-10 Year of Tropical Convection (YOTC) and the 2011 Dynamics of the Madden-Julian Oscillation (DYNAMO), are used to study these phenomena. These datasets reveal the frequent occurrence of shed and nonshed terrain-induced cyclonic circulations over the IO, the majority of which occur during boreal fall and winter. During the $2.5 \mathrm{yr}$ of the two campaigns, 13 wake vortices $(13 \%$ of the shed circulations identified) were tracked and observed to subsequently develop into TCs over the northern and southern IO, accounting for $25 \%$ of the total TCs forming in the IO during that period.
\end{abstract}

\section{Introduction}

A number of processes, acting singly or in concert, have been observed to contribute to tropical cyclone (TC) formation [e.g., African easterly waves (AEWs), convectively coupled equatorial waves, breakdown of the intertropical convergence zone (ITCZ), monsoon troughs, and upper-level troughs]. It has also been proposed that topographic effects may influence TC formation. This possibility has been explored for the eastern Pacific Ocean by Farfán and Zehnder (1997) and Zehnder et al. (1999). These studies found that easterly flow impinging upon zonally and diagonally oriented mountain ranges in Central America and Mexico can

Supplemental information related to this paper is available at the Journals Online website: http://dx.doi.org/10.1175/ MWR-D-16-0102.s1.

Corresponding author address: Richard H. Johnson, Department of Atmospheric Science, 1371 Campus Delivery, Colorado State University, Fort Collins, CO 80523.

E-mail: johnson@atmos.colostate.edu generate along-mountain jets and lee vortices. These features then combine with AEWs and moist flow out of the ITCZ to initiate tropical cyclogenesis. This paper investigates another possible topographic influence on TC formation; namely, the generation of vortices by the large cross-equatorial island of Sumatra and neighboring topographic features, a phenomenon originally proposed by Kuettner (1989).

\section{a. Terrain-induced circulations: Roles of Sumatra and surrounding topography}

When stratified flow is blocked by an isolated obstacle, counter-rotating vortices may form in its wake as flow diverts to either side of the barrier and converges downstream (Smolarkiewicz and Rotunno 1989; Rotunno and Smolarkiewicz 1991). When the Froude number (U/Nh, where $U$ is the approaching wind speed, $N$ is the BruntVäisälä frequency, and $h$ is the obstacle height) is less than 1 , flow blocking is preferred. Generally, flow will be split or blocked below some critical height, and will flow over the obstacle above that critical height (Smolarkiewicz and Rotunno 1989). There can be a production of potential 


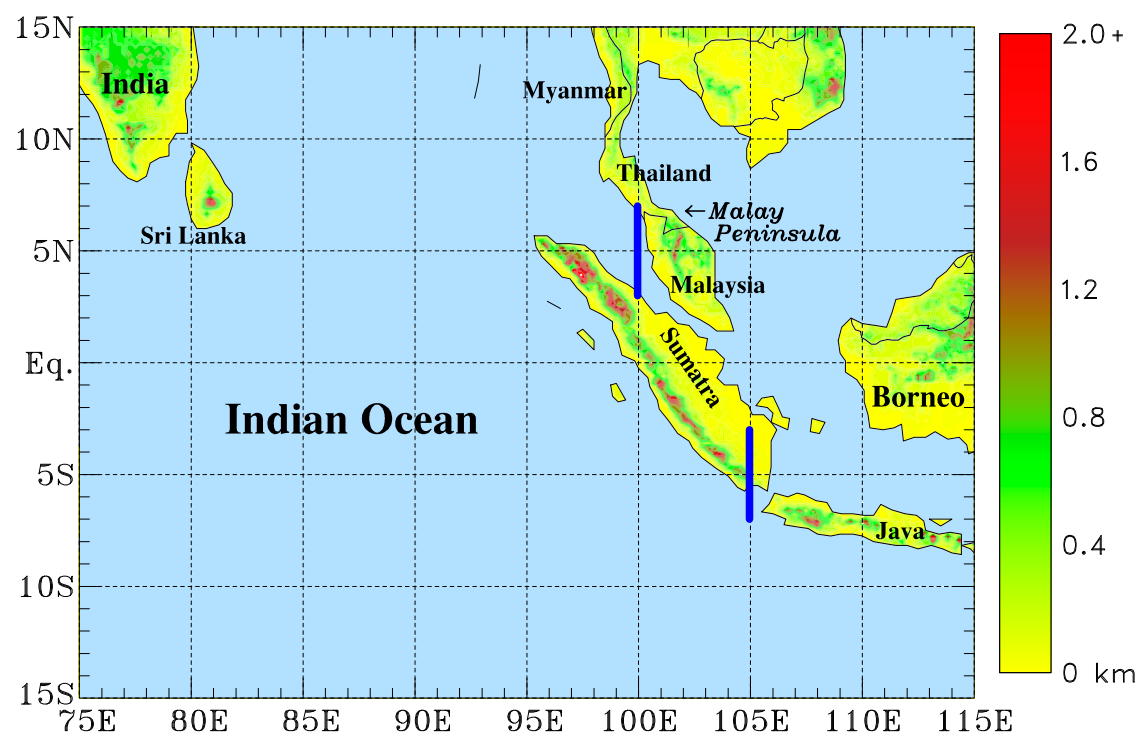

FIG. 1. Analysis domain and topography $(\mathrm{km})$ of the region (elevation scale on right). Delineation of flow regimes is based on zonal wind analyzed along blue lines at $3^{\circ}-7^{\circ} \mathrm{N}, 100^{\circ} \mathrm{E}$ and $3^{\circ}-7^{\circ} \mathrm{S}, 105^{\circ} \mathrm{E}$.

vorticity in the wake vortices if the flow surmounting the barrier undergoes a hydraulic jump, along with an associated slight reduction in the surface pressure (Schär and Smith 1993a; Epifanio and Durran 2002; Epifanio 2003). For elongated barriers such as Sumatra, wave breaking, flow splitting, and the development of lee vortices depend not only on the Froude number (the inverse of which is the nondimensional mountain height), but also on the horizontal aspect ratio of the barrier (the ratio of the cross-stream length scale to the streamwise length scale of the barrier) (Smith 1989; Epifanio 2003). For typical flow conditions around many islands in the tropics and subtropics, lee vortices are commonplace. These vortices often shed and move downstream as a result of boundary layer separation, perturbations in the flow, or instability in the wake (Etling 1989; Schär and Smith 1993b). Sumatra is one such island where the conditions for flow splitting and lee vortex formation are met.

In this study, it is proposed that flow blocking and splitting by the topography on the island of Sumatra and adjacent topographic features-the mountainous west end of Java and the Malay Peninsula - can lead to eventual TC genesis in the Indian Ocean. In this region, the mean flow impacting the terrain features is principally monsoonal, with easterlies in the winter hemisphere and westerlies in the summer hemisphere. With respect to Sumatra, a narrow mountain range stretches along its entire length, from approximately $6^{\circ} \mathrm{N}$ to $6^{\circ} \mathrm{S}$, exceeding $3000 \mathrm{~m}$ in elevation near the island's northern tip (Fig. 1). Easterly wind blocked by the island will result in wake vortices over the Indian Ocean in each hemisphere that will rotate in opposite directions, but since the island straddles the equator, both are cyclonic. This unique situation is not found elsewhere in the tropics. It is proposed that these wake vortices may then serve as preexisting cyclonic disturbances out of which TCs may develop. Such a possibility was first explored by Kuettner $(1967,1989)$, who argued that the splitting of easterly flow by Sumatra was responsible for sets of twin cyclones in the Indian Ocean and, using satellite imagery, traced these TCs back to wake vortices observed downstream of Sumatra under low-level easterly flow regimes.

However, it is evident from Fig. 1 that for easterly flow there are other islands and topographic features in the Maritime Continent that can potentially have an impact on the circulation downstream over the Indian Ocean. As it turns out, the features other than Sumatra of greatest significance with respect to lee vortex generation affecting the Indian Ocean are the Malay Peninsula and the island of Java. For the Malay Peninsula, it will be seen that easterly flow directed around the Titiwangsa Mountains in the south and across the narrow island gap to the north can lead to lee vortices that impinge upon or skirt the north end of Sumatra. On the other hand, southeasterly flow impinging on the high terrain of west Java also leads to the generation of lee vortices downstream, which upon shedding then pass the southern tip of Sumatra.

Westerly flow impinging on Sumatra may also result in downstream wake vortices, but these are both anticyclonic and occur over the islands and inland seas of the Maritime Continent, so TC formation related to this 
flow blocking situation is not a possibility. However, given the high terrain all along the western side of Sumatra (Fig. 1), blocking of equatorial westerly flow by the barrier may also contribute cyclonic circulations upstream of the island as the flow splits near the equator and moves north and south. This topographic effect will be seen to be yet another factor in TC formation over the Indian Ocean, thus expanding upon the idea originally advanced by Kuettner (1989) regarding the blocking of low-level easterly flow by the island. There have been previous studies of the blocking of westerly flow by Sumatra in the context of the passage of the MJO (Inness and Slingo 2006; Wu and Hsu 2009) and convectively coupled Kelvin waves (Ridout and Flatau 2011) over the Maritime Continent.

\section{b. Other factors influencing the formation of tropical cyclones}

The potential for intensification of terrain-induced vortices into TCs over the eastern Indian Ocean is affected by seasonal and intraseasonal variability of the flow. As noted, easterly wind impinging upon Sumatra may be blocked and generate cyclonic lee vortices in both hemispheres. One source of low-level easterly wind in the Indian Ocean is the Madden-Julian oscillation (MJO; Madden and Julian 1971, 1972), which is the dominant mode of intraseasonal tropical variability (e.g., Zhang 2005). In the Indian and western Pacific Oceans, the MJO is characterized by low-level easterly winds preceding the arrival of an eastward-propagating convective envelope or active phase, followed by lowlevel westerly winds. Wake vortices developing over the Indian Ocean downstream of Sumatra in the easterly flow, once shed, may then traverse an environment with enhanced moisture and divergence aloft, thus aiding TC genesis. Recently, Duvel (2015) showed that the MJO enhances the frequency of TC genesis over the southern Indian Ocean by increasing both the number of tropical depression initiations and the probability of their intensification. The increased frequency is attributed to the MJO enhancing the cyclonic meridional shear of the zonal wind in the TC genesis latitudes.

The Southeast Asian and Australian monsoons also exert an influence on tropical cyclogenesis in the Indian Ocean Basin. When the summer and winter monsoons are established, strong vertical wind shear discourages tropical cyclogenesis (Gray 1968). During the transition period into the winter monsoon, the vertical shear is reduced so that when the low-level flow is easterly, cyclonic vortices that develop over the Indian Ocean west of Sumatra have a greater opportunity for eventual intensification into a TC. Indeed, in the limited years that he analyzed, Kuettner (1989) observed TCs intensifying out of wake vortices generated by Sumatra between October and December, and in May, which represent the monsoon transition periods.

Synoptic- and local-scale meteorological phenomena also complicate conditions associated with wake vortices developing near Sumatra. Convectively coupled equatorial waves, such as equatorial Rossby or Kelvin waves, have been shown to assist tropical cyclogenesis (Bessafi and Wheeler 2006; Frank and Roundy 2006; Roundy 2008; Schreck and Molinari 2009, 2011; MacRitchie and Roundy 2012; Schreck 2015). In addition, there is frequently a pronounced diurnal cycle of convection over and in proximity to Sumatra (e.g., Mori et al. 2004; Qian 2008; Wu et al. 2009). This diurnal cycle may have a further influence on circulations that develop locally around the island including their shedding and movement away from the barrier.

\section{c. Goals of the study}

Analysis of terrain-induced vortex formation by topographic features in and around Sumatra and its possible role in TC formation over the Indian Ocean are explored using datasets from two field campaigns: the 2008-10 Year of Tropical Convection (YOTC) and the OctoberMarch 2011-12 Dynamics of the MJO (DYNAMO) experiment. Although the analysis period is limited to $2.5 \mathrm{yr}$, data from these campaigns were selected because of their high resolution $\left(0.25^{\circ}\right.$ grid $)$, their widespread use for studying tropical convection, and in the case of DYNAMO, the assimilation of field campaign data over the Indian Ocean into the analyses. Despite the high resolution, the actual processes by which the incipient circulations induced by terrain are transformed into TCs (i.e., TC genesis itself) are not adequately resolved by the datasets and are thus beyond the scope of this study. This work represents a preliminary investigation of this phenomenon, intended to motivate further process studies, as well as longer-term climatologies of topographic effects on TC formation over the Indian Ocean.

\section{Data and methods}

\section{a. Data}

The data for this study are from the YOTC and DYNAMO campaigns. YOTC was a "virtual" field experiment, conducted between May 2008 and April 2010, with a focus on gathering and assimilating existing sources of data, such as those from satellite observations or buoys, to better understand and simulate many tropical phenomena (Moncrieff et al. 2012). There were six active MJO events noted during YOTC, which passed by Sumatra in June and September 2008; February, April, and 
November 2009; and April 2010 (Waliser et al. 2012). The active phases of the April 2009 and later MJO occurrences featured stronger convection, and remained intact and propagated farther east than did the other YOTC MJO events (Waliser et al. 2012).

The DYNAMO campaign involved in situ measurements by radiosonde, ship, and aircraft-based instruments in the Indian Ocean Basin, where the MJO typically initiates (Yoneyama et al. 2013; Johnson and Ciesielski 2013). The special observing period (SOP), which featured the greatest spatial and temporal density of observations, ran from 1 October to 15 December 2011, followed by a period of less-intense observations through the end of March 2012. There were two MJO events during the DYNAMO SOP: in October and November. The November MJO event was noted for its strong convection, two westerly wind bursts, and the interaction of Kelvin waves, equatorial Rossby waves, and nascent TC development over the northern Indian Ocean (Gottschalck et al. 2013; Kerns and Chen 2014; Judt and Chen 2014; Oh et al. 2015).

A reanalysis dataset for YOTC (1 May 2008-30 April 2010) and the operational analysis (OA) dataset for DYNAMO (1 October 2011-31 March 2012) were produced by the European Centre for Medium-Range Weather Forecasts (ECMWF). These datasets were created by a component of ECMWF's global model running at an enhanced resolution with observations during YOTC and DYNAMO assimilated into the model (Moncrieff et al. 2012; Johnson and Ciesielski 2013). For both datasets, the spatial resolution is $0.25^{\circ}$, with 18 pressure levels available between the surface and $50 \mathrm{hPa}$, and the temporal resolution is 6-hourly. It should be kept in mind that the YOTC period is $2 \mathrm{yr}$, whereas the DYNAMO period is 6 months, so comparison of annual distributions from the two campaigns is not possible.

As a proxy for convective activity, outgoing longwave radiation $(\mathrm{OLR})$ data at $1^{\circ}$ resolution from the National Oceanic and Atmospheric Administration (NOAA) Earth System Research Laboratory (ESRL), Boulder, Colorado (www.esrl.noaa.gov/psd; Lee 2014) have been utilized.

Tropical cyclone track, intensity, and naming designations were obtained from best track data from the Joint Typhoon Warning Center (JTWC) as well as from NOAA's International Best Track Archive for Climate Stewardship (IBTrACS) website (www.ncdc.noaa.gov/ ibtracs).

\section{b. Methods and definition of analysis regions}

To determine the origin of terrain-induced circulations that ultimately led to $\mathrm{TC}$ genesis, a procedure is needed to identify and track the circulation features. While most of the prominent circulations can be
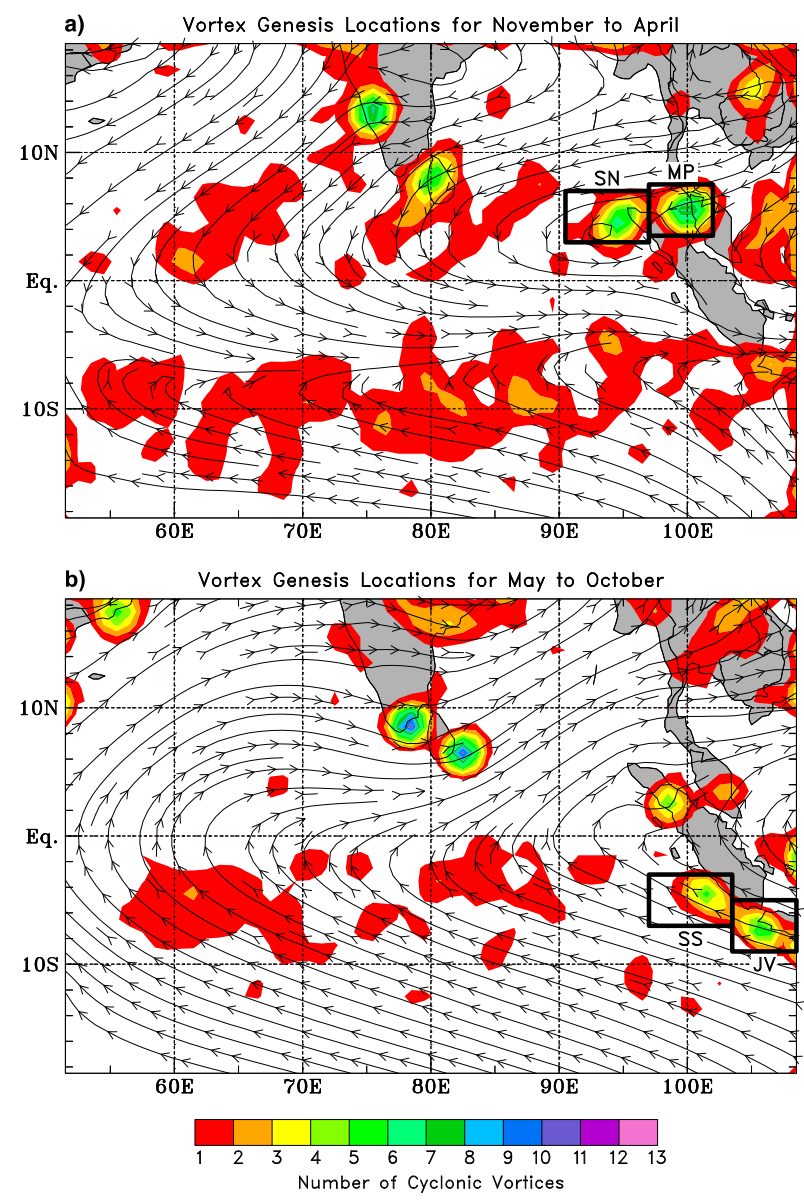

FIG. 2. Cyclonic vortex genesis counts on a $1^{\circ}$ grid for (a) November-April and (b) May-October periods. Streamlines depict 925-850-hPa layer-averaged flows. Flows in (a) and (b) typify boreal winter and summer monsoon conditions, respectively.

identified and tracked subjectively, the limitations of such an approach as well as the large number of cases during the $2.5 \mathrm{yr}$ of study of both nonshed and shed circulations, demands that an objective procedure be used. Hence, the identification and tracking of vortices was carried out using the objective feature tracking code of Hodges $(1995,1999)$. While the cyclonic circulation features were commonly associated with negative height anomalies, as shown by Duvel (2015) for the southern Indian Ocean, many of the circulations tracked very close to or even crossed the equator, which has led to the use of relative vorticity for tracking. Relative vorticity fields at $6 \mathrm{~h}$ and $0.25^{\circ}$ horizontal resolution from the YOTC analyses (May 2008-April 2010) and ECMWF OA (October 2011-March 2012) were vertically averaged over the 925-850-hPa layer, then smoothed to retain spatial scales greater than $450 \mathrm{~km}$. Sensitivity tests showed that changes to the smoothing cutoff length had 
TABLE 1. Vortices (shed and nonshed) and tropical cyclones originating from the four analysis regions in Fig. 2, including totals for easterly $\left(U_{N}<0\right.$ for SN and MP, $U_{S}<0$ for SS and JV) and westerly $\left(U_{N}>0\right.$ for SN and MP, $U_{S}>0$ for SS and JV) flow regimes.

\begin{tabular}{|c|c|c|c|c|c|}
\hline & \multicolumn{4}{|c|}{ Genesis region } & \multirow[b]{2}{*}{ Total } \\
\hline & Sumatra north (SN) & Malay Peninsula (MP) & Sumatra south (SS) & Java (JV) & \\
\hline Total vortices & 73 & 85 & 74 & 77 & 309 \\
\hline Shed vortices (total) & 43 & 15 & 25 & 20 & 103 \\
\hline Shed vortices (easterly flow) & 40 & 12 & 18 & 19 & 89 \\
\hline Shed vortices (westerly flow) & 3 & 3 & 7 & 1 & 14 \\
\hline Nonshed vortices (total) & 30 & 70 & 49 & 57 & 206 \\
\hline Nonshed vortices (easterly flow) & 26 & 61 & 36 & 40 & 163 \\
\hline Nonshed vortices (westerly flow) & 4 & 9 & 13 & 17 & 43 \\
\hline Tropical cyclones & 5 & 0 & 6 & 2 & 13 \\
\hline
\end{tabular}

no notable impact on the identification of vortices. The vertical averaging of vorticity was used to improve the temporal coherency of features when a vorticity maximum shifts between different model levels (Serra et al. 2010). Cyclonic vorticity features were tracked if their peak amplitude was greater than $1.0 \times 10^{-5} \mathrm{~s}^{-1}$ and they persisted for longer than 2 days. This threshold is larger than that used by Serra et al. (2010) for African easterly waves, but sensitivity tests show that this value effectively captures significant vortex features that have the potential to contribute to TC genesis.

To focus on vortex wakes that transitioned into Indian Ocean tropical storms, we restrict our analyses only to cases in which the vortex shed westward over the Indian Ocean. To differentiate between westward-shedding and nonshed vortices, shed vortices are defined as those with 1) a final location over the Indian Ocean that is $>500 \mathrm{~km}$ from Sumatra, and either 2) final minus initial distance from Sumatra is $>250 \mathrm{~km}$, or 3 ) their average speed away from Sumatra is $>0.5 \mathrm{~m} \mathrm{~s}^{-1}$. Condition 1 ensures that the shed vortex at the end of its track is some critical distance from Sumatra and conditions 2 or 3 ensure that it is moving away from this landmass.

Application of the tracking code to the $2.5 \mathrm{yr}$ of data yields information on both genesis locations and tracks of the cyclonic vortices. Genesis locations are shown in Fig. 2, separately for the boreal cold (NovemberApril) and warm (May-October) seasons. During the boreal winter monsoon (Fig. 2a), northeasterly flow across the Malay Peninsula and the northern tip of Sumatra produces a high frequency of lee vortices just downstream of these topographic features. To quantify relationships between the flow and downstream circulations in these regions (to be shown later), two analysis boxes are defined in Fig. 2a: Sumatra north (SN) and Malay Peninsula (MP). There are also genesis maxima across the northern parts of Sri Lanka and the Western Ghats, as well as a broad area of genesis sites (unrelated to topography) in the southern ITCZ (Duvel 2015).

During the boreal summer monsoon, southeasterly flow across west Java and the southern tip of Sumatra leads to two genesis maxima in those locations (Fig. 2b). Regions Sumatra south (SS) and Java (JV), defined for later analyses, encompass these maxima. Similar to SN and MP, these regions are downstream of the relevant topographic features, indicating the majority are wake vortices. There are also maxima at the southern tip of India and southeast of Sri Lanka, as well as through a gap in the Bukit Barisan mountain range on Sumatra. However, these maxima, as well as those over India and Sri Lanka in the cold season, likely do not contribute to TC genesis, so they will not be considered in our analysis.

To delineate easterly and westerly flow regimes, which determine where terrain-induced vortices will form and move in relation to the topography, two computation line segments are identified in Fig. $1\left(3^{\circ}-7^{\circ} \mathrm{N}, 100^{\circ} \mathrm{E}\right.$ and $\left.3^{\circ}-7^{\circ} \mathrm{S}, 105^{\circ} \mathrm{E}\right)$. Averages of the zonal wind along these lines (defined as $U_{N}$ and $U_{S}$, respectively) are considered representative of the flow in the analysis boxes adjacent to them. To determine the likelihood of flow blocking or splitting by the topographic features in the regions, Froude numbers were evaluated in proximity to these line segments using zonal wind speed and Brunt-Väisälä frequency averaged over the 950-850-hPa layer and assuming average terrain heights of 1.0 and $0.5 \mathrm{~km}$ in the north and south, respectively.

To identify convectively coupled equatorial waves and their relationship to the wake vortices and TC genesis, OLR anomalies were calculated from the NOAA OLR data, then filtered for different wave mode characteristics-period, wavenumber, and equivalent depth (Wheeler and Kiladis 1999)—which identify Kelvin, equatorial Rossby, MJO-type, or mixed Rossby-gravity waves (code provided by K. Straub 2014, personal communication). 
TABLE 2. Yearly and summary totals of tropical cyclones (TCs) in the northern and southern Indian Ocean (IO) that formed to the west of $105^{\circ} \mathrm{E}$ during YOTC and DYNAMO, including numbers and percentages of tropical cyclones originating from terraininduced vortices. Numbers in parentheses are means from a $30-\mathrm{yr}$ (1985-2014) climatology of TCs that formed in the IO Basin, indicating that the TC activity during the YOTC-DYNAMO periods was close to the long-term means.

\begin{tabular}{lccc}
\hline \hline Period & Northern IO & Southern IO & Total \\
\hline YOTC & & & \\
2008 (May-Dec) & $6(4.8)$ & $4(4.3)$ & $10(9.1)$ \\
2009 (Jan-Dec) & $5(5.3)$ & $13(12.3)$ & $18(17.6)$ \\
2010 (Jan-Apr) & $0(0.5)$ & $7(8.0)$ & $7(8.5)$ \\
DYNAMO & & & \\
2011 (Oct-Dec) & $5(3.1)$ & $3(3.1)$ & $8(6.2)$ \\
2012 (Jan-Mar) & $0(0.3)$ & $8(6.9)$ & $8(7.2)$ \\
Total & 16 & 35 & 51 \\
No. of TCs from & 5 & 8 & 13 \\
$\quad$ terrain vortices & & & \\
Percent TCs from & 31.3 & 22.9 & 25.5 \\
$\quad$ terrain vortices & & & \\
\hline
\end{tabular}

\section{Results}

\section{a. Vortex statistics and tracks}

Terrain-induced vortices that moved westward out over the Indian Ocean and had the potential to contribute to TC genesis originated in the four analysis boxes shown in Fig. 2. Therefore, these regions are identified as the focal areas for subsequent analyses. Statistics on shed and nonshed vortices from these four regions are presented in Table 1 . A total of 309 cyclonic vortices were detected in the four regions during the $2.5 \mathrm{yr}$ of data, 103 (33\%) of which were shed (i.e., moved downstream away from their point of origination). The vast majority $(90 \%)$ of the shed circulations from SN and MP occurred during easterly flow, hence, were lee or wake vortices that detached from the terrain features. A similar high percentage $(95 \%)$ of shed vortices occurred along west JV in easterly flow. The frequency for SS during easterly flow $(72 \%)$ was somewhat less, indicating there were a fair number of cases with westerly flow impinging on Sumatra contributing to cyclonic circulations off the southern tip of the island. Flow conditions associated with shedding in all regions will be shown in section $3 b$.

Also indicated in Table 1, there were 13 terraininduced vortices that subsequently developed into named TCs: 5 from SN, 6 from SS, and 2 from JV. In other words, $13 \%$ of the 103 shed vortices eventually became TCs during the $2.5 \mathrm{yr}$ of study. Tracks and other information pertaining to these events will be shown later; however, a summary of these 13 events and their relationship to the total named tropical cyclone counts in the Indian Ocean Basin ${ }^{1}$ for the various YOTC and DYNAMO time periods is shown in Table 2. The five TCs over the northern IO originating from terraininduced circulations represent $31 \%$ of the total (16) TCs in that region during the 2.5 -yr period, whereas the 8 TCs similarly identified for the southern IO represent $23 \%$ of the total (35) for that region. Notably, for the entire IO Basin, the 13 TCs originating from shed vortices represent $25 \%$ of the total (51) TCs occurring in the Indian Ocean Basin during the period of study, highlighting the important role of topography in TC formation in this region. Moreover, these percentages likely represent a lower bound to such events since they include only cases in which the tracking program provided conclusive evidence of a wake to TC transition. Other cases may not have been captured due to limitations in the reanalysis datasets and the limitations imposed by the various tracking procedure settings (e.g., a lower vorticity amplitude threshold may have yielded longer, more continuous tracks). Finally, Table 2 also includes average $\mathrm{TC}$ frequencies (values in parentheses) based on a $30-\mathrm{yr}$ (1985-2014) climatology of TC formation in the IO using JTWC best track and storm report data. It can be seen that the TC frequencies for the different time periods for this longer-term climatology are comparable to those for the $2.5 \mathrm{yr}$ of YOTC and DYNAMO, indicating that the more limited period in our study was not abnormal in terms of TC activity.

The monthly distributions of the shed and nonshed vortices, as well as TCs originating from terrain-induced circulations, for regions SN and MP are shown in Fig. 3. Values are shown in counts per year to take into account the fact that the data records for YOTC $(2 \mathrm{yr})$ and DYNAMO (6 months) are different. From Fig. 3 it is seen that cyclonic vortices generated by the topographic features in SN and MP occur predominantly during the boreal winter monsoon, when low-level easterly flow prevails over the region (Figs. $2 \mathrm{a}$ and $3 \mathrm{c}$ ). Shedding of vortices is more common from SN than MP (Table 1), and only $\mathrm{SN}$-shed vortices (5 cases in October and November, representing $12 \%$ of the shed events) led to TC genesis during the $2.5 \mathrm{yr}$ of study.

Cyclonic vortices from regions SS and JV are distributed somewhat more broadly throughout the annual cycle (Fig. 4), although the majority occurred during the austral winter and spring seasons. On average, the flow across these terrain features during this period had an

\footnotetext{
${ }^{1}$ The Indian Ocean Basin is defined here as that portion of the Indian Ocean extending from Africa to $105^{\circ} \mathrm{E}$. Tropical cyclones that formed east of $105^{\circ}$ and moved into the Indian Ocean are excluded from the tabulations.
} 

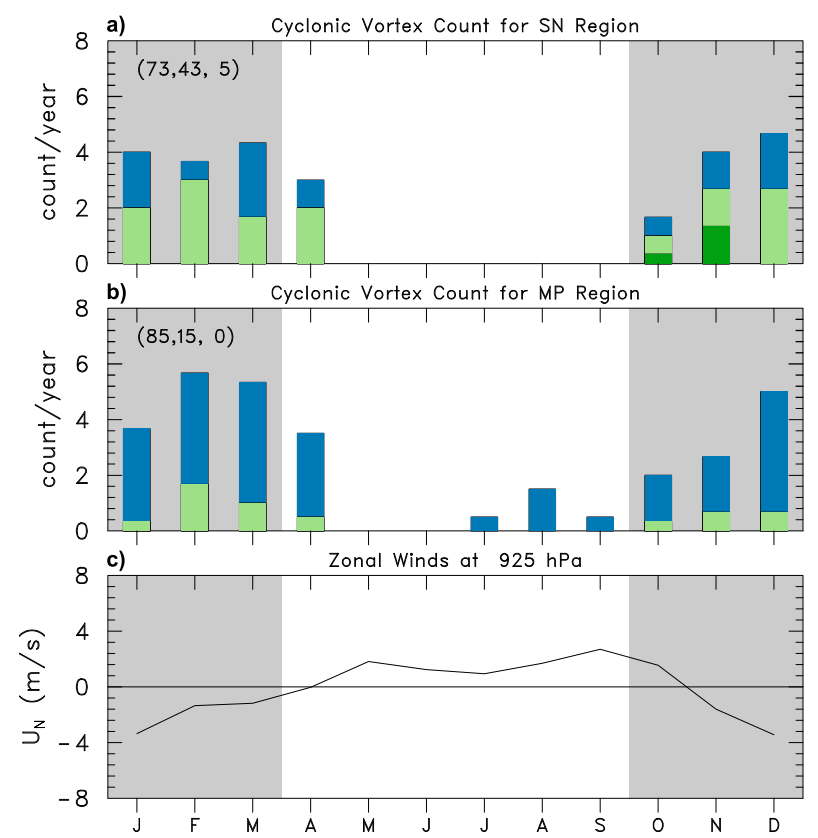

FIG. 3. Monthly frequency of terrain-induced shed (top of lightgreen bars) and nonshed (length of blue bar segments) cyclonic vortices for (a) Sumatra north (SN) and (b) Malay Peninsula (MP) regions. (c) Monthly mean zonal wind $\left(\mathrm{m} \mathrm{s}^{-1}\right)$ along $100^{\circ} \mathrm{E}$ (line segment shown in Fig. 1), indicating most cyclonic vortices in these regions occur in mean low-level easterly flow during the boreal winter monsoon. The frequency of $\mathrm{TC}$ events originating from terrain-induced vortices is shown by the dark green bars. Gray shading indicates a period of time with $3 \mathrm{yr}$ of data from both YOTC and DYNAMO; unshaded period has only $2 \mathrm{yr}$ of YOTC data.

easterly component (Figs. $2 \mathrm{~b}$ and $4 \mathrm{c}$ ). Similar to the northern Sumatra region, those terrain-induced cyclonic vortices that led to TC genesis occurred around the times of transition between easterly and westerly flow. With respect to timing, most TC cases (5 out of 8 ) in the southern Indian Ocean occurred during the boreal winter monsoon, as was the case in region SN.

To further emphasize the importance of the topography surrounding the Indian Ocean Basin for initiating cyclonic circulations, a map of all vortex tracks originating between $10^{\circ} \mathrm{N}$ and $10^{\circ} \mathrm{S}$ in this region during the $2.5 \mathrm{yr}$ of data is shown in Fig. 5a. The role of significant terrain features-Sumatra, the Malay Peninsula, west Java, southern India, and Sri Lanka-for generating cyclonic circulations is clearly evident. Many of the circulations produced by SN and MP move due westward, whereas those from SS and JV are frequently swept northwestward off the southern coast of Sumatra by the southeasterly flow (Fig. 2b). Tracks emanating from Sri Lanka and the south tip of India occur predominantly during the fully developed winter and summer monsoons and likely do not contribute to
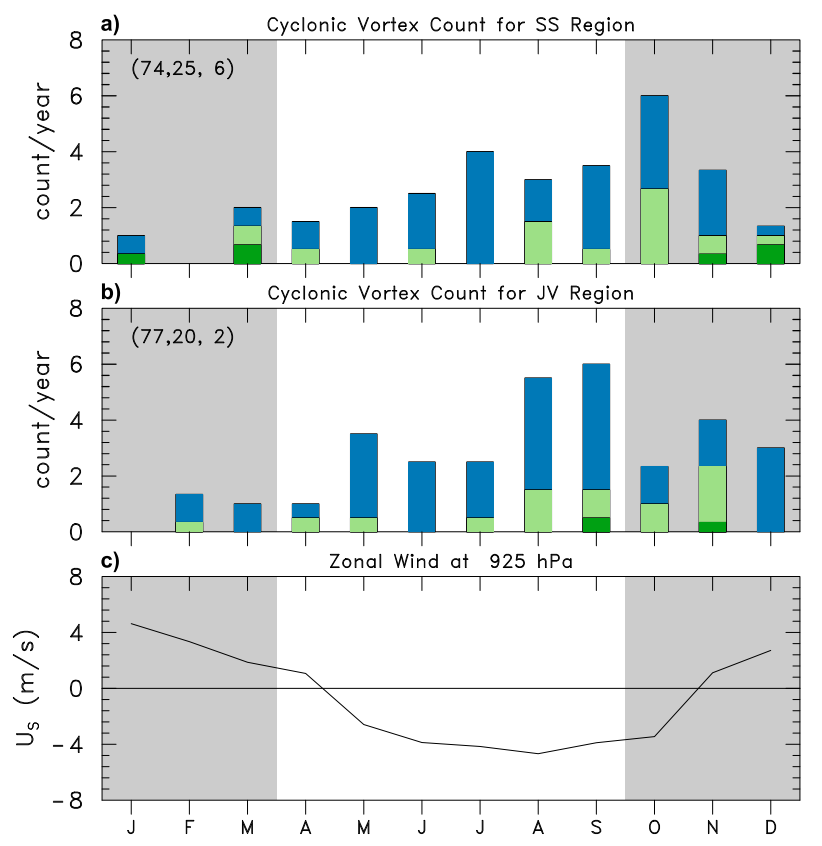

FIG. 4. As in Fig. 3, but for (a) Sumatra south (SS) and (b) west Java (JV) regions. (c) Monthly mean zonal wind $\left(\mathrm{m} \mathrm{s}^{-1}\right)$ along $105^{\circ} \mathrm{E}$ (line segment shown in Fig. 1), indicating cyclonic vortices in these regions can occur during both easterly and westerly mean flow.

TC genesis due to stronger vertical shear during these periods.

The tracks of the cyclonic circulations emanating from the four analysis boxes are shown in Fig. 5b. Most tracks extend westward over the Indian Ocean and, hence, potentially can contribute to TC genesis. Indeed, a number of the tracks, including some spanning most of the entire Indian Ocean, eventually became named TCs, as will be shown later.

As mentioned earlier, shedding of wake vortices may be a result of boundary layer separation, perturbations in the flow, or instability in the wake (Etling 1989; Schär and Smith 1993b). Comparison of the mean lower-tropospheric flow for shed and nonshed vortices (easterly flow cases only) for region SN (Fig. 6) reveals rather subtle flow differences across the northern tip of Sumatra. Specifically, shed events have a slightly stronger easterly flow to the north of the island (up to $2 \mathrm{~m} \mathrm{~s}^{-1}$ at $700 \mathrm{hPa}$ ), perhaps aiding the shedding process. Similar differences are noted for shed versus nonshed easterly flow cases for region SS (not shown). Furthermore, additional analyses of the $\mathrm{SN}$ cases (also not shown) indicates that for shed cases, easterly flow in the vicinity of $\mathrm{SN}$ increases and peaks 1-2 days following the initiation date of the wake vortex, whereas for nonshed cases, easterly flow diminishes following wake vortex initiation.

The mean flow for shed cases for region SS for both easterly and westerly flow is shown in Fig. 7. Cyclonic 

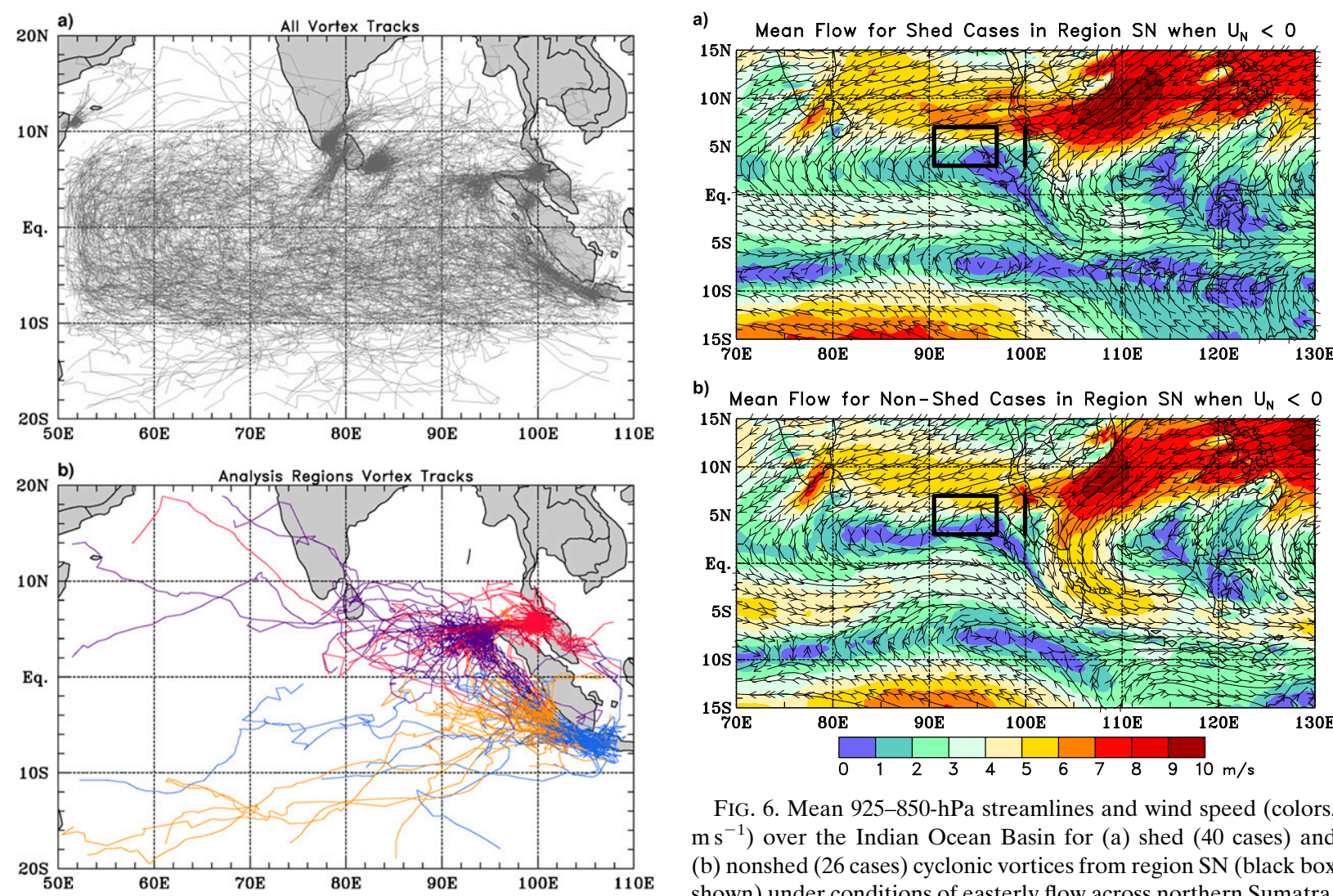

b) Mean Flow for Non-Shed Cases in Region SN when $U_{N}<0$

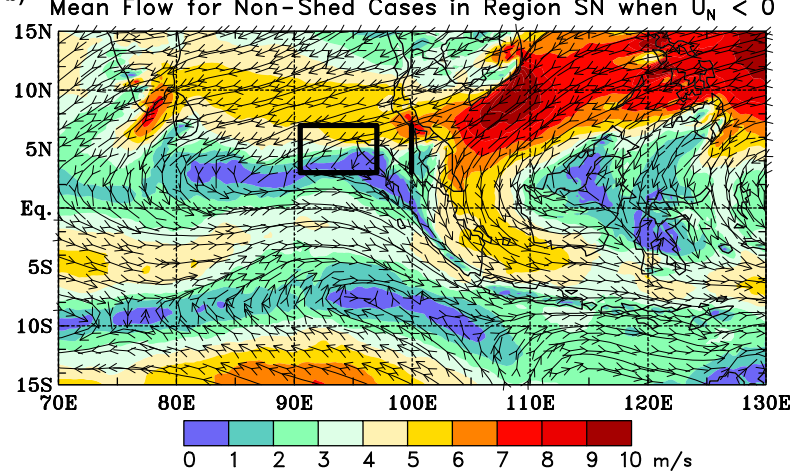

FIG. 6. Mean 925-850-hPa streamlines and wind speed (colors, $\mathrm{m} \mathrm{s}^{-1}$ ) over the Indian Ocean Basin for (a) shed (40 cases) and (b) nonshed (26 cases) cyclonic vortices from region SN (black box shown) under conditions of easterly flow across northern Sumatra. The $U_{N}$ is the average zonal flow shown along the vertical black line to the east of the black rectangular box.

2 . 5. (a) Tracks for all cyclonic vortices lasting longer th by the objective tracking scheme. Prominent origination sites can be seen near Sumatra, the Malay Peninsula, west Java, southern India, and Sri Lanka. (b) As in (a), but only for cyclonic vortices emanating from the four analysis regions: Sumatra north (SN, purple), Malay Peninsula (MP, red), Sumatra south (SS, orange), and west Java (JV, blue).

vortex generation over the eastern Indian Ocean south of the equator in easterly flow (Fig. 7a) is in part created by southeasterly flow against the mountain barrier along the southern part of the island. However, in addition, blocking of westerly flow along and just to the north of the equator by the island is seen to partially contribute to the cyclonic circulation in this region. This effect is particularly noticeable for westerly flow in region SS (Fig. 7b), where upstream blocking and splitting of equatorial westerly flow is seen to contribute to cyclonic circulations in both hemispheres. However, the flow pattern for this situation is also suggestive of a pair of Rossby gyres, which would be accompanied by equatorial westerlies impinging on Sumatra. Such a case was studied by Ridout and Flatau (2011), where the Rossby gyres near Sumatra were associated with a convectively coupled Kelvin wave. Nevertheless, blocking of equatorial westerlies by the topography of Sumatra could serve to enhance the

circulations in the Rossby gyres, representing a superposition of effects contributing to vortex initiation.

\section{b. Vorticity production by topography}

Topographically generated vorticity streamers, similar to "PV banners" investigated during the Mesoscale Alpine Programme (Aebischer and Schär 1998), are seen to be commonplace throughout the Asian-Australian monsoon region (Fig. 8). Streamlines and relative vorticity for the 6-month DYNAMO period are shown in Fig. 8a for easterly $925-850-\mathrm{hPa}$ flow across northern Sumatra $\left(U_{N}\right)$ having a magnitude exceeding $5 \mathrm{~m} \mathrm{~s}^{-1}$. A positive vorticity maximum is observed at the northern tip of Sumatra, consistent with the observation of frequent vortex generation just downstream (Fig. 2a). A streamer of vorticity extends due westward into the Indian Ocean, suggestive of frequent shedding of these vortices. The average Froude number (Fr) in the 950-850-hPa layer under the easterly flow regimes was $\sim 0.3$, supporting flow blocking and splitting by Sumatra's mountains (Smith 1989; Smolarkiewicz and Rotunno 1989). Positive vorticity is also observed downstream of the northern periphery of other islands in the Maritime Continent such as 


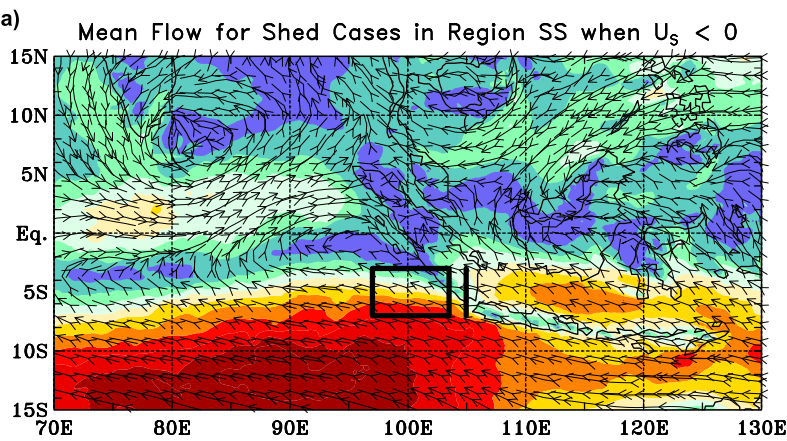

b) Mean Flow for Shed Cases in Region SS when $U_{S}>0$

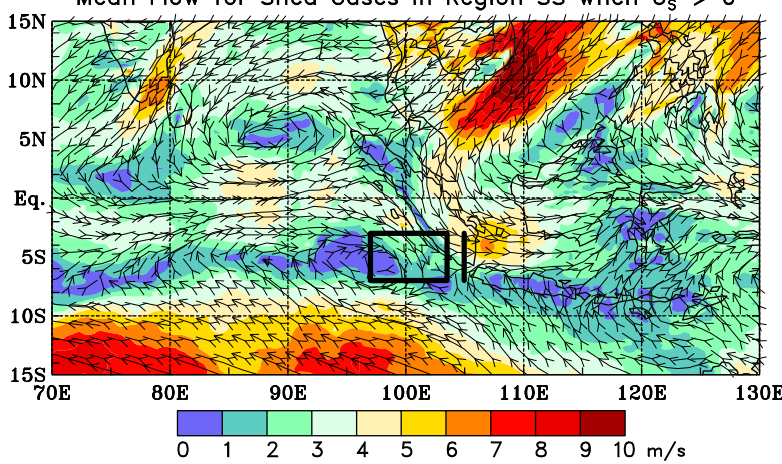

FIG. 7. As in Fig. 6, but for shed vortices from region SS with (a) easterly (18 cases) and (b) westerly (7 cases) flow, where $U_{S}$ is the average zonal flow along the vertical black line at $105^{\circ} \mathrm{E}$.

Borneo, the island of Sri Lanka, and significant topographic features elsewhere in the region. Negative geopotential height anomalies were observed in the center of these cyclonic vortices (not shown here, but illustrated later), consistent with the findings of Schär and Smith (1993b).

For the flow conditions used to produce Fig. 8a, cyclonic vorticity can also be seen downstream of the southern tip of Sumatra, with a closed circulation offshore extending into a broad expanse of negative vorticity across most of the Indian Ocean between the equator and $10^{\circ} \mathrm{S}^{2}$ This broad trough region reflects the existence of the southern Indian Ocean ITCZ. Froude numbers associated with easterly flow for the southern regions were $\sim 0.7$, suggesting a slightly weaker blocking effect by the southern portion of the island, principally due to the lower average topography there (Fig. 1).

During low-level westerly flow across the northern tip of Sumatra, anticyclonic relative vorticity was observed

\footnotetext{
${ }^{2}$ The flow pattern illustrated in Fig. 8a closely resembles that depicted by Kuettner (1989) as an archetype of the circulation associated with twin cyclone development in the eastern Indian Ocean, leading him to propose Sumatra as a potential generator of incipient TC disturbances.
}
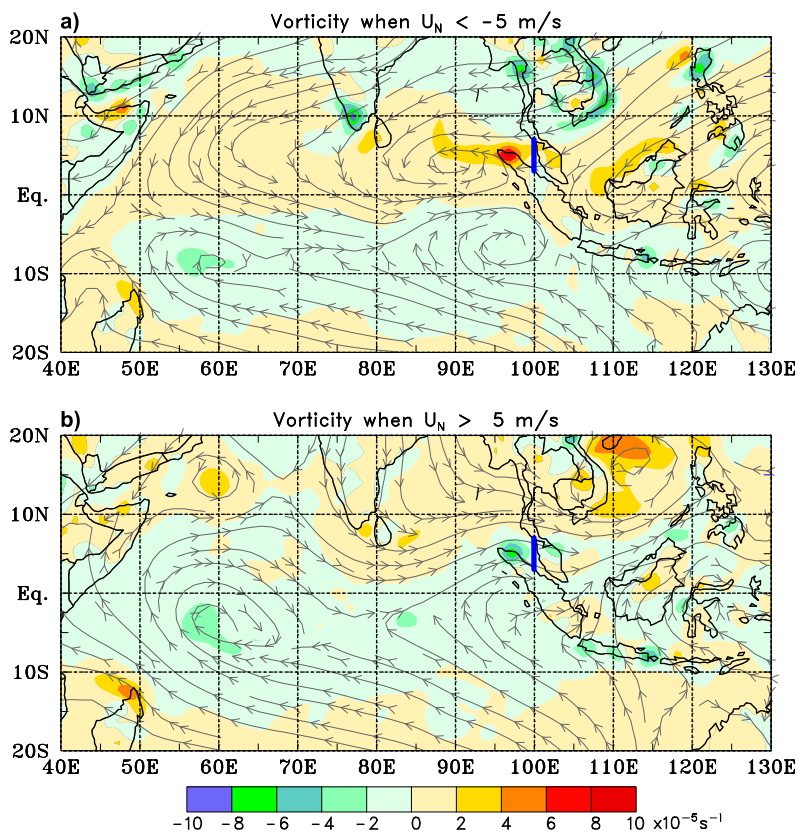

FIG. 8. Mean 925-850-hPa streamlines and relative vorticity $\left(\times 10^{-5} \mathrm{~s}^{-1}\right.$, scale at bottom) during DYNAMO (October 2011March 2012) for all (a) easterly and (b) westerly wind days, as determined by the zonal wind incident upon northern Sumatra. Fields shown are means for days when $\left|U_{N}\right|>5 \mathrm{~m} \mathrm{~s}^{-1}$, where $U_{N}$ is the zonal wind averaged along the vertical blue line at $100^{\circ} \mathrm{E}$. Panels (a) and (b) include 97 and 23 total 6-hourly analyses, respectively.

along Sumatra's northern tip (Fig. 8b), as well as to the lee of the Malay Peninsula and at the north coast of Borneo. During this period, the southern ITCZ (indicated by cyclonic or negative vorticity) was still present, though shifted slightly equatorward.

To better quantify the relationship between zonal wind and the circulation downstream of Sumatra, relative vorticity averaged within each of the analysis regions was regressed onto zonal winds $U_{N}$ or $U_{S}$ (as appropriate for their respective hemispheres) at different levels in the lower troposphere. Peak correlations were found to occur in the height range from the $925-850-\mathrm{hPa}$ level in the north and the 950-1000-hPa level in the south, with correlations dropping off at higher levels (Fig. 9). This behavior is consistent with expected flow blocking for topography with an average height of $1-2 \mathrm{~km}$ in the northern Sumatra region and somewhat lower in the south. The weaker correlations near the surface in regions $\mathrm{SN}, \mathrm{MP}$, and SS are likely related to weaker surface flow in those areas due to blocking by topography, while the differing correlation patterns at higher levels are related to different mean flow patterns in the north versus south regions. Considering these findings, a level of $900 \mathrm{hPa}$ is chosen to illustrate correlations between 


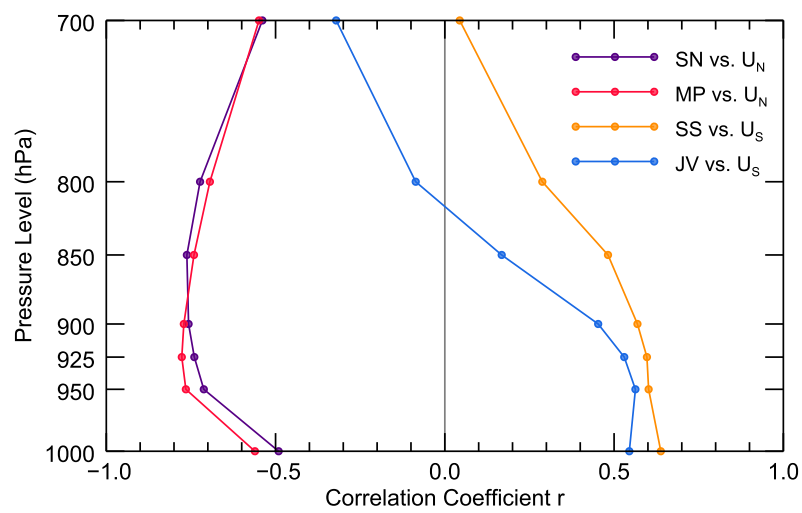

FIG. 9. Correlations between relative vorticity $\zeta$ and zonal wind speeds $U_{N}$ and $U_{S}$ along northern and southern line segments, respectively, in Fig. 1 during the $2.5 \mathrm{yr}$ of YOTC and DYNAMO for regions SN (purple), MP (red), SS (orange), and JV (blue). Since portions of analysis regions include mountainous areas, computations are restricted only to grid points above ground level. The magnitudes of the correlations maximize in the lower troposphere (between $925-850 \mathrm{hPa}$ in the north and $950-1000 \mathrm{hPa}$ in the south), indicating the key role of topography in generating the low-level circulations.

zonal wind and relative vorticity for all four regions (Fig. 10). For the entire 2.5-yr period, cyclonic (positive) vorticity in regions SN and MP (Fig. 10, top panels) was negatively correlated to the zonal wind (all correlations significant at the $99 \%$ level). In other words, the stronger the oncoming flow, the stronger the vorticity in the analysis regions.

In regions SS and JV (Fig. 10, bottom panels), correlations between $900-\mathrm{hPa}$ zonal wind and relative vorticity were poorer than those for the northern regions. This is not unexpected since the average topography is lower in the south (Fig. 1). In addition, the mean vorticity is nearly always cyclonic off the southwest coast of Sumatra due to the relatively persistent ITCZ, which migrates north and south throughout the year (Fig. 2). The persistence of cyclonic vorticity near southern Sumatra regardless of flow direction is evident in Fig. 10 (bottom panels) where most of the relative vorticity values are negative for easterly flow cases and the majority are also negative for westerly flow cases.

\section{c. Vortex shedding as a precursor to tropical cyclone development}

Once formed, terrain-produced vortices often shed and move downstream. Potential vorticity anomalies within the circulations can persist as they move downstream, unless acted upon by dissipative processes. While it would be instructive to elucidate the mechanisms for shedding in our study region, data adequate to do so (e.g., field campaign data in proximity to Sumatra) are not available.
The formation and downstream movement of cyclonic vortices for the latitudes of both northern and southern Sumatra are shown for the YOTC and DYNAMO years in wind-vorticity Hovmöller diagrams for the OND period in Figs. 11-13. All of the TCs traced back to cyclonic vortices generated by Sumatra's topography in the northern Indian Ocean during the YOTC and DYNAMO periods occurred during the months of OND (Table 3). During the OND periods for all three years, positive vorticity maxima at $850 \mathrm{hPa}$ frequently occur near $95^{\circ} \mathrm{E}$ in region SN just west of Sumatra's northern tip (Figs. 11a, 12a, and 13a). Similarly, in Figs. 11-13, frequent vorticity maxima can also be seen at the longitudes of the other regions: MP $\left[\sim\left(100^{\circ}-102^{\circ} \mathrm{E}\right)\right]$, SS $\left(\sim 100^{\circ} \mathrm{E}\right)$, and $\mathrm{JV}$ $\left(\sim 105^{\circ} \mathrm{E}\right)$. Farther east, other positive-negative vorticity anomalies are evident and associated with terrain features in the Maritime Continent (Fig. 8a).

The common occurrence of positive vorticity maxima at the longitude of Sumatra's northern tip during easterly flow is evidence of persistent lee vortex formation. On occasion, however, the positive vorticity anomalies detach from Sumatra and move westward. Three instances of such events directly associated with TC development in 2008 are depicted in Fig. 11a: TC 03A in October, Nisha in November, and TC 07B in December. $^{3}$

A similar pattern of cyclonic (negative) vorticity maxima near $95^{\circ} \mathrm{E}$ just west of Sumatra's southern tip is seen in Fig. 11b (fields are at $925 \mathrm{hPa}$ due to lower topography there) although its association solely with easterly flow is less obvious than in northern Sumatra. One westward-moving vorticity streamer in October was a precursor to TC Asma, the southern Indian Ocean counterpart to TC 03A.

During the 2009 OND YOTC period, vorticity maxima once again occurred near Sumatra's northern tip associated with lee vortex formation, and several instances of shedding vortices were evident in November (Fig. 12a). However, TC Ward was the only northern Indian Ocean storm during the OND 2009 period to develop from a lee vortex. Over the southern Indian Ocean, TCs Cleo and David (Fig. 12b) formed around the time of TC Ward, collectively constituting cross-equatorial "triplets" in December 2009. Cleo and David both reached tropical storm wind speeds following the end of vorticity streamers depicted within

\footnotetext{
${ }^{3}$ In the case of TC $03 \mathrm{~A}$ and several others shown later, the location of the storm symbol is displaced outside the vorticity streamer in the time-longitude diagrams since the official naming of the TC occurred when the center was outside the $3^{\circ}-7^{\circ}$ latitude band.
} 

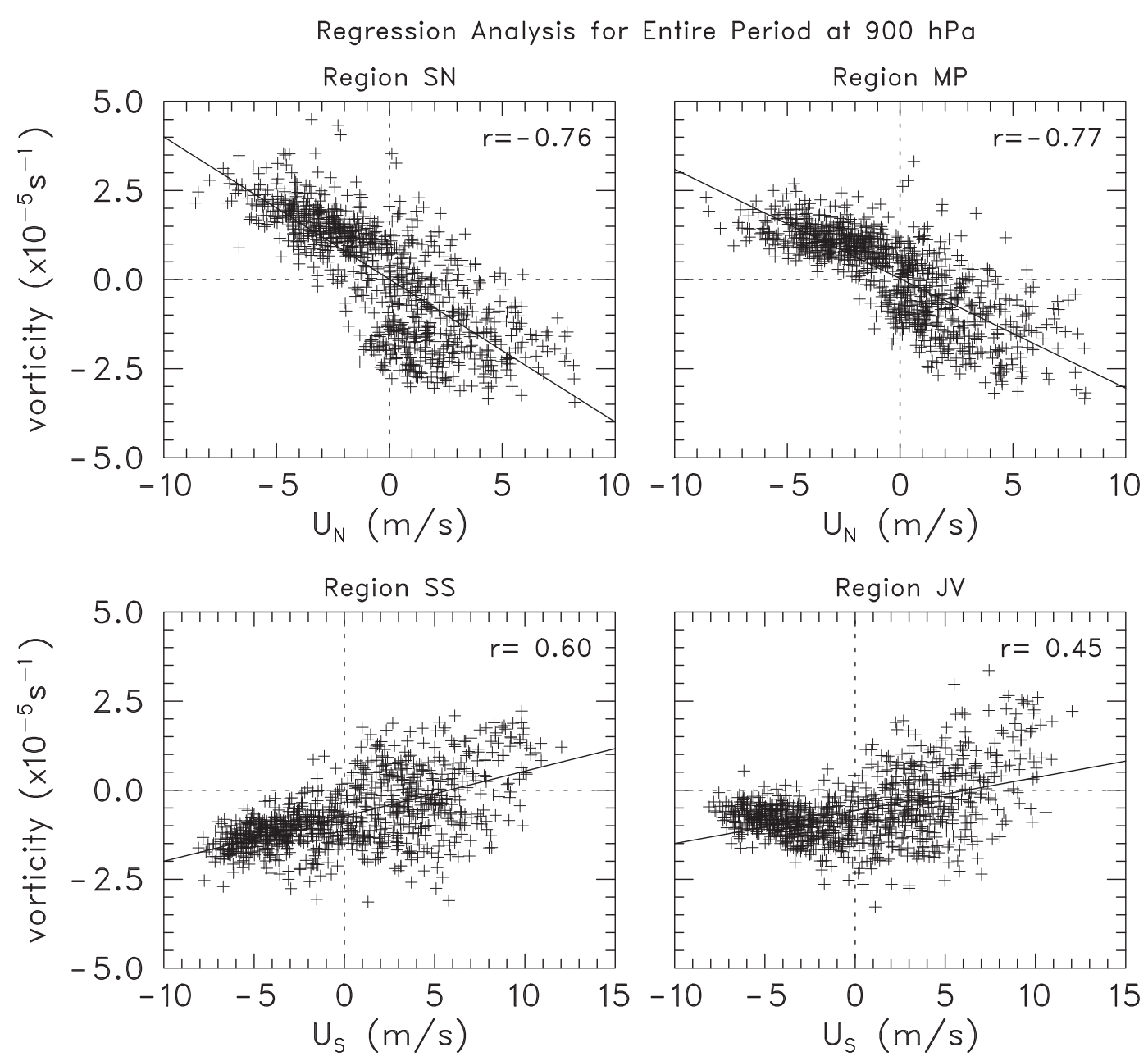

FIG. 10. Relative vorticity regressed onto average zonal wind speeds $U_{N}$ and $U_{S}$ at $900 \mathrm{hPa}$ along northern and southern line segments, respectively, in Fig. 1 during the $2.5 \mathrm{yr}$ of YOTC and DYNAMO for regions SN, MP, SS, and JV. Each data point consists of a concurrent daily averaged relative vorticity and zonal wind value. Solid lines are linear least squares best fits to the data. Correlation coefficients $r$ are indicated in the top right of each panel.

the southern Sumatra latitude band (Fig. 12b), although it is difficult to identify each storm with a particular shed vortex in this depiction since the wake vortices moved out of the $3^{\circ}-7^{\circ} \mathrm{S}$ latitude band before intensifying. The continuity of these circulations will become more apparent in the discussion of individual cases in section $3 \mathrm{~d}$.

During the DYNAMO year, the three instances where wake vortices propagated westward and eventually became tropical cyclones-TC 05A in the Northern Hemisphere and TCs Alenga and Benilde in the Southern Hemisphere-are indicated in Fig. 13. There are also a number of shed wake vortices (vorticity streamers) in both hemispheres that did not develop into tropical cyclones. However, two of the TCs that developed, 05A and Alenga, moved into a favorable environment for
TC genesis provided by the developing MJO over the central Indian Ocean (Yoneyama et al. 2013; Gottschalck et al. 2013). Prominent vorticity maxima immediately to the west of Sumatra's tips regularly occurred during periods of low-level easterly flow at $850 \mathrm{hPa}$ in both the Northern (Fig. 13a) and Southern (Fig. 13b) Hemispheres, with westward movement of streamers in a number of instances.

In summary, results for the YOTC and DYNAMO years indicate that when easterly wind impinged upon Sumatra, multiple wake vortices were observed to form and propagate away in succession [e.g., in November 2009 (Fig. 12a), and in the easterly wind periods that preceded the late October and November 2011 MJO events (Fig. 13a)]. However, in some instances, as will be evident in the cases presented later, augmentation of 
a) $3 \mathrm{~N}-7 \mathrm{~N}$ at $850 \mathrm{hPa}$ for OND 2008

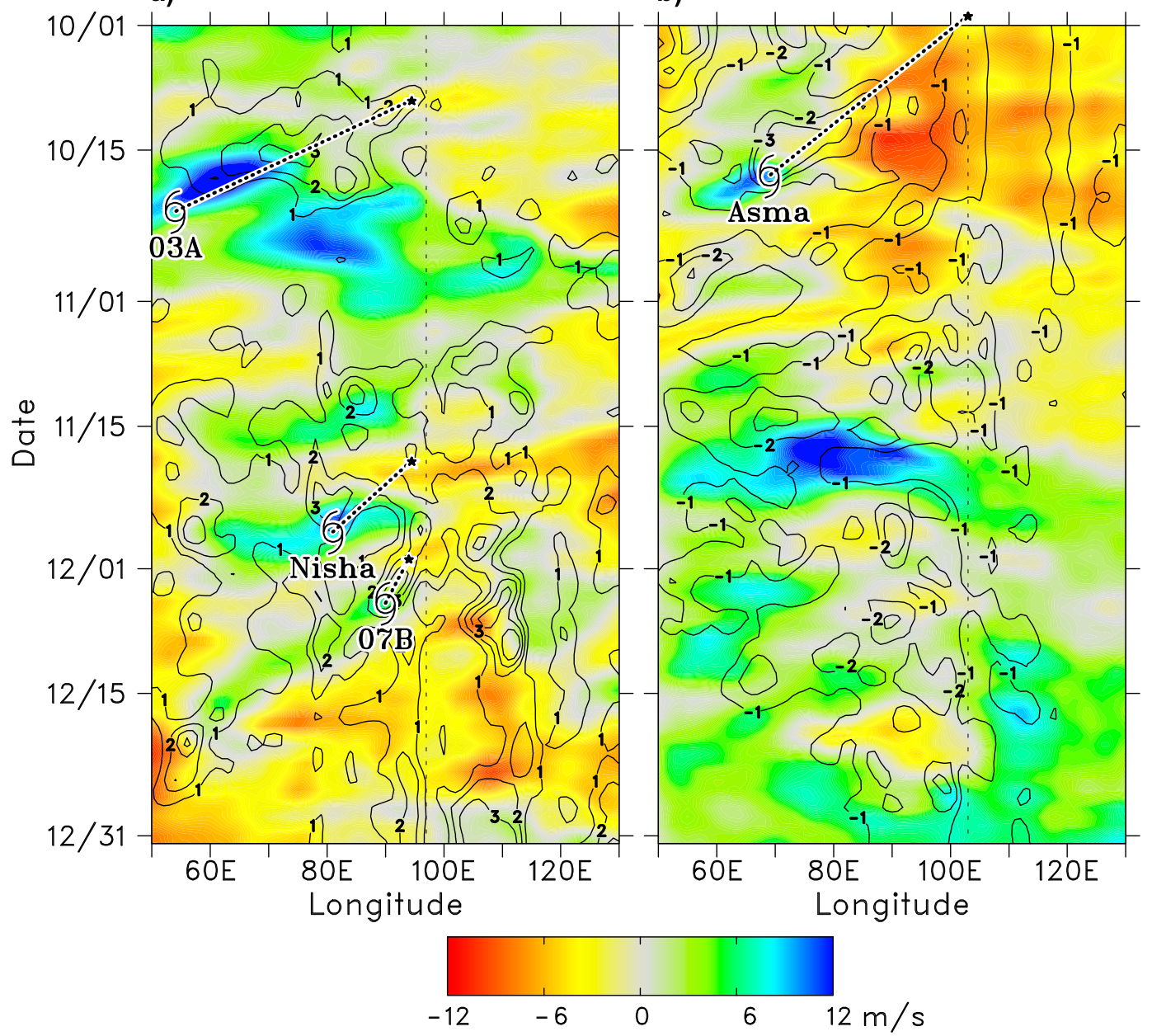

FIG. 11. Time-longitude diagrams of daily averaged zonal wind $\left(\mathrm{m} \mathrm{s}^{-1}\right.$, color, scale at bottom) and relative vorticity (contours, plotted only for cyclonic vorticity starting at $\left|1 \times 10^{-5} \mathrm{~s}^{-1}\right|$ with a contour interval of $1 \times 10^{-5} \mathrm{~s}^{-1}$ ) for OND2008 at (a) $850 \mathrm{hPa}$, averaged over $3^{\circ}-7^{\circ} \mathrm{N}$, and (b) $925 \mathrm{hPa}$, averaged over $3^{\circ}-7^{\circ} \mathrm{S}$. Origins of vortices that later became TCs are indicated by black stars, and longitudes and dates when vortices became named TCs are shown by the tropical cyclone symbol. Dotted lines point to the initial vortex from which the TC formed. Faint vertical dashed lines denote longitudes of northern (a) and southern (b) tips of Sumatra. TCs may move out of the latitude averaging bands, which may account for apparent discrepancies between the "end" of a vorticity streamer and the location of tropical cyclogenesis.

cyclonic vorticity appeared to occur when westerly equatorial wind impacted central Sumatra as well. In these situations, the high terrain on the western side of Sumatra blocked low-level equatorial westerly flow, diverting it to the north and south, so that when combined with easterly flow across Sumatra's tips, cyclonic vorticity was enhanced in those locations.

The southern Indian Ocean near Sumatra demonstrated a weak secondary maximum in shed vortex occurrence between March and May (Figs. 4a,b), another period of climatologically frequent tropical cyclogenesis in the Indian Ocean. Two TCs originating from terrain-induced vortices from region SS occurred during this period (in March), while another occurred in January (Fig. 4b). The remaining Southern Hemisphere TCs traced back to terrain-induced vortices (five of them) occurred between October and December.

In total, 10 TCs during YOTC, and 3 during DYNAMO, were determined to have developed from cyclonic vortices that formed downstream of Sumatra and adjacent land masses. Three TCs, Gael (2009) during YOTC and 05A and Alenga (2011) during DYNAMO, formed in the easterly flow regimes preceding the active phase of MJO events. The tracks of all of the wake vortices that eventually developed into tropical cyclones during the $2 \mathrm{yr}$ of YOTC and the DYNAMO SOP are 


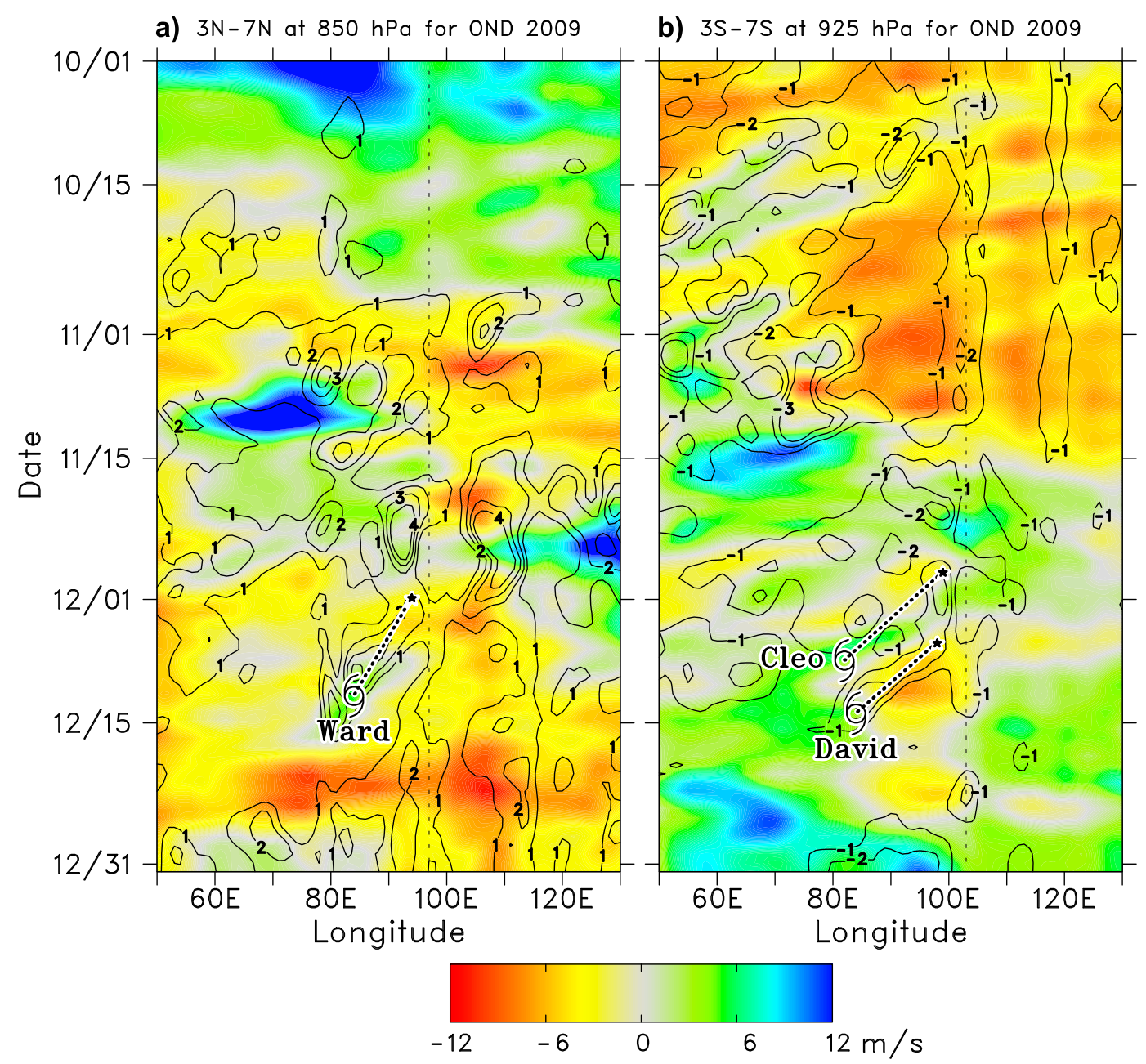

FIG. 12. As in Fig. 11, but for OND2009.

plotted in Fig. 14. The pre-TC periods of the tracked vortices are marked by thin lines, the named-storm periods are marked by thick lines. Several of the vortices remained coherent and traversed much of the Indian Ocean Basin before they intensified and were named by the responsible agencies, while others intensified closer to Sumatra. Three sets of cross-equatorial, companion tropical cyclones that originated from wake vortices during the analyzed time periods were TCs $03 \mathrm{~A}$ and Asma in October 2008; TCs Cleo, Ward, and David in December 2009; and TCs 05A and Alenga in late November and early December 2011. [Animations of the 925-850-hPa vorticity, geopotential height, and wind fields for four TC cases-TC 07B (2008), TC Cleo (2009), TC 05A (2011), and TC Alenga (2011)—are provided in the online supplemental material.]

The 13 TCs identified to have originated from terraininduced circulations during YOTC and DYNAMO are listed in Table 3. The length of time from vortex genesis to naming of the storms by operational centers ranged from 5 to 20 days, with an average duration of 10.1 days, indicating a long gestation period for many of the disturbances prior to TC genesis. Comparing results from Tables 1 and 2, 9\% (18\%) of the vortices identified using the vorticity threshold of $1.0 \times 10^{-5} \mathrm{~s}^{-1}$ that shed from the northern (southern) regions of Sumatra, or $13 \%$ of the total, eventually became named TCs. As mentioned earlier, these TCs comprised one-quarter of all TCs occurring in the Indian Ocean Basin during the period of study.

\section{d. Selected case studies}

In this section, tropical cyclones Cleo, Ward, and David in 2009 and 05A in 2011 have been selected to illustrate cyclonic vortex development, associated geopotential height falls, and subsequent transformation into TCs. Detailed mechanisms involved in their transformations (i.e., the process of TC genesis) cannot be 


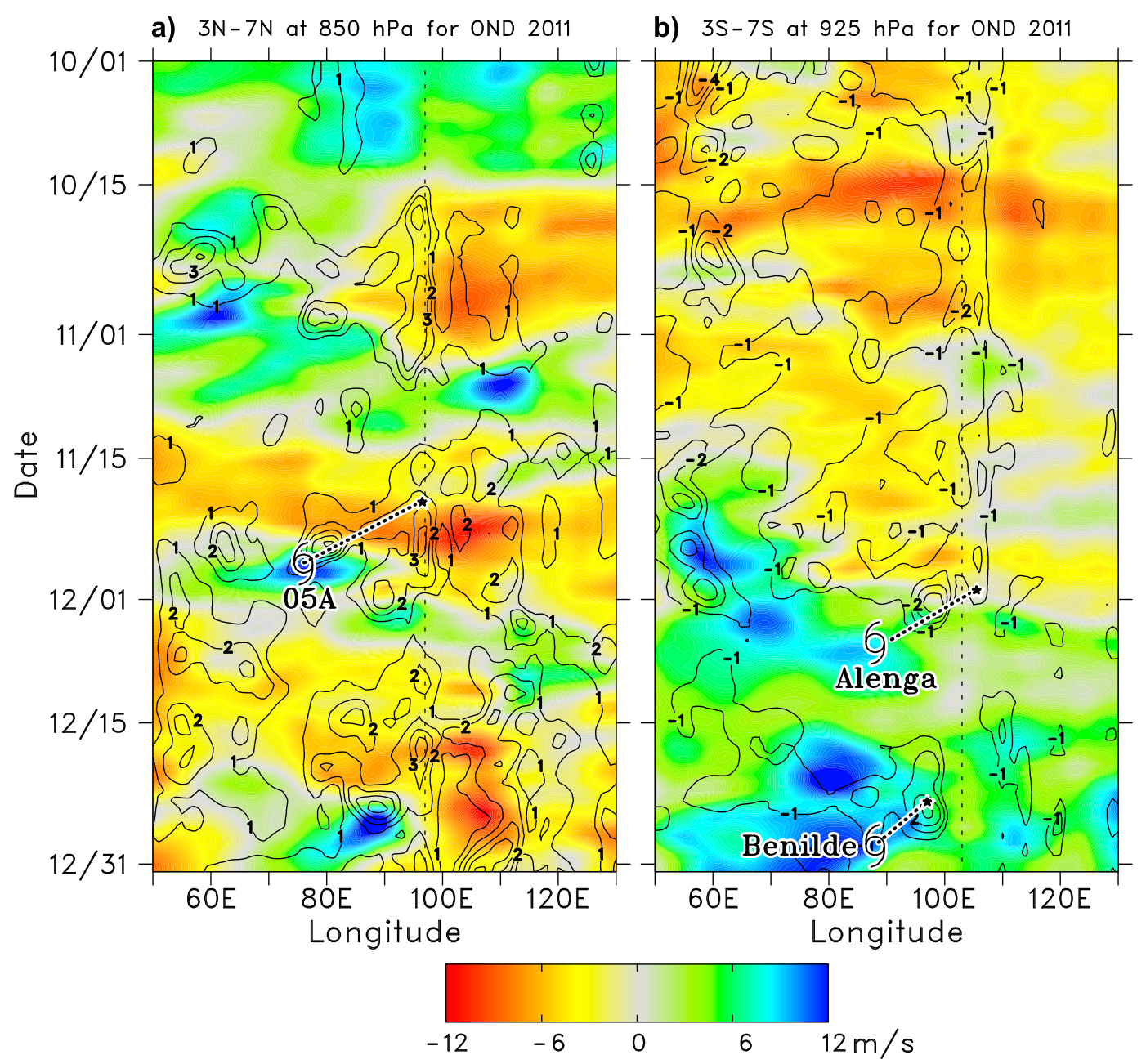

FIG. 13. As in Fig. 11, but for OND2011.

fully determined from the available data, so this aspect of their life cycles is beyond the scope of this study. The full tracks of the TCs, beginning as wake vortices near Sumatra, are shown in Fig. 14.

Tropical cyclones Cleo, Ward, and David can be considered "triplet" storms in December 2009. The wake vortex precursor to TC Cleo in the Southern Hemisphere appeared to be assisted by blocking of westerly equatorial flow by central Sumatra in late November 2009. The vortex is near $100^{\circ} \mathrm{E}$ on 2 December with lower geopotential heights already at its center (Fig. 15a). Cleo eventually became a named storm on 7 December. At the same time, a lee vortex appeared on the north end of the island, which would eventually become TC Ward on 11 December (Figs. 14 and 15b,c). Low-level flow near southern Sumatra shifted to easterly on 3 December and along with blocked equatorial westerlies resulted in a second cyclonic wake vortex in the southern Indian Ocean, which would later move westward and intensify into TC David (Figs. 15e,f), which was named on 13 December. In the cases of all three storms, no apparent upstream cyclonic vorticity maxima were present prior to the wake vortex initiation (Fig. 12). Strong $\left(u>7 \mathrm{~m} \mathrm{~s}^{-1}\right)$ low-level equatorial westerlies were present over the eastern Indian Ocean through the life cycle of these burgeoning wake vortices, which, together with low-level trade easterlies farther poleward, constituted cyclonic shear in both hemispheres. At their peak intensities, TCs Cleo and Ward had estimated winds up to 115 and $45 \mathrm{kt}$, respectively. Tropical Cyclone David reached the middle of the Indian Ocean before intensifying into a tropical storm with a maximum wind speed of $55 \mathrm{kt}$. Its remnants dumped heavy rain on Mauritius and Reunion, causing flooding and damage (Tuyau 2009). There was not an MJO event prior to TCs Cleo, Ward, and David, to create environmental conditions that may have enhanced the potential for TC genesis, as in the 2011 (DYNAMO) cases of TC 05A and Alenga, which will be discussed next. 
TABLE 3. The 13 terrain-induced vortices that developed into named tropical cyclones originating from three analysis regions in Fig. 2-Sumatra north (SN), Sumatra south (SS), and Java (JV)—during YOTC and DYNAMO.

\begin{tabular}{|c|c|c|c|c|c|}
\hline Storm name & Yr & $\begin{array}{l}\text { Vortex initiation } \\
\text { region }\end{array}$ & $\begin{array}{l}\text { First detection } \\
\text { date }\end{array}$ & $\begin{array}{l}\text { TC naming date } \\
\text { (JTWC) }\end{array}$ & $\begin{array}{c}\text { Pre-TC } \\
\text { duration (days) }\end{array}$ \\
\hline Asma & 2008 & JV & $27 \mathrm{Sep}$ & 17 Oct & 20 \\
\hline $03 \mathrm{~A}$ & 2008 & $\mathrm{SN}$ & 8 Oct & 21 Oct & 13 \\
\hline Nisha & 2008 & $\mathrm{SN}$ & 18 Nov & 26 Nov & 8 \\
\hline 07B & 2008 & $\mathrm{SN}$ & 29 Nov & $4 \mathrm{Dec}$ & 5 \\
\hline Gael & 2009 & SS & 15 Jan & $3 \mathrm{Feb}$ & 19 \\
\hline Cleo & 2009 & SS & 27 Nov & $7 \mathrm{Dec}$ & 10 \\
\hline Ward & 2009 & SN & 29 Nov & $11 \mathrm{Dec}$ & 12 \\
\hline David & 2009 & SS & $5 \mathrm{Dec}$ & $13 \mathrm{Dec}$ & 8 \\
\hline Imani & 2010 & SS & $11 \mathrm{Mar}$ & $23 \mathrm{Mar}$ & 12 \\
\hline Robyn & 2010 & SS & $26 \mathrm{Mar}$ & $2 \mathrm{Apr}$ & 7 \\
\hline $05 \mathrm{~A}$ & 2011 & SN & 19 Nov & $26 \mathrm{Nov}$ & 7 \\
\hline Alenga & 2011 & JV & 30 Nov & $5 \mathrm{Dec}$ & 5 \\
\hline Benilde & 2011 & SS & $23 \mathrm{Dec}$ & $28 \mathrm{Dec}$ & 5 \\
\hline
\end{tabular}

In late November 2011, the wake vortex that would later become TC 05A initiated off the north tip of Sumatra as easterly flow impinged upon the island (Fig. 16a). These low-level easterlies were associated with the preonset phase of the approaching November 2011 MJO convective envelope (Johnson and Ciesielski 2013). The vortex moved slowly westward over the next four days (Figs. 16c-f), but was not officially designated TC 05A until 26 November when it was west of Sri Lanka and had encountered the moist MJO convective envelope. Though its maximum wind speed was only $35 \mathrm{kt}$, it caused damage and deaths in Sri Lanka (http:// www.webcitation.org/63Vnhm01u). The wake vortex that would become TC Alenga formed 10 days after the TC 05A vortex and, therefore, is not depicted in Fig. 16, though it too interacted with the MJO convective envelope (in a way likely similar to that described by Duvel 2015) to assist in its development, namely, by encountering enhanced north-south shear of the low-level zonal flow.

The development of TC $05 \mathrm{~A}$ was also influenced by convectively coupled equatorial waves, which occurred in association with the late November 2011 active MJO event (Gottschalck et al. 2013; Oh et al. 2015). A convectively coupled equatorial Rossby (ER) wave moved westward and passed over the vorticity streamer that represents the wake vortex precursor to TC $05 \mathrm{~A}$ in late November (Fig. 17a). The initiation of the vorticity streamer around 22 November was nearly coincident with the arrival of the ER wave at the longitude of Sumatra. However, investigation of all the other cases with respect to the passage of equatorial waves (equatorial Rossby and mixed Rossby-gravity) did not show any consistent or systematic pattern of vortex shedding in association with the waves (not shown). In addition, a Kelvin wave convective envelope, which featured strong OLR anomalies, propagated eastward over the same region in late November 2011 (Fig. 17b). Its encounter with the wake vortex on 25 November led to a pronounced strengthening of the vorticity at that time. Strong westerly wind bursts, apparent in Figs. 16e and 16f, associated with the Kelvin waves likely served to enhance the vortex's low-level cyclonic circulation. Gottschalck et al. (2013) and Oh et al. (2015) describe the combined influence of Kelvin, equatorial Rossby, and mixed Rossby-gravity waves on the flow in the region of the developing TC 05A during this period.

\section{Summary and conclusions}

This study explores the potential role of the island of Sumatra and adjacent topographic features in creating terrain-induced circulations over the Indian Ocean that later develop into tropical cyclones (TCs). Sumatra, as well as the Malay Peninsula and Java, have mountainous terrain that partially blocks low-level flow under typical environmental stratification. For easterly low-level flow, these terrain features often produce lee vortices, some of which subsequently shed and move westward from the northern and southern tips of Sumatra and thence downstream over the Indian Ocean. Since Sumatra straddles the equator, extending in a northwest-southeast direction from approximately $6^{\circ} \mathrm{N}$ to $6^{\circ} \mathrm{S}$, the lee vortices generated at the two ends, while counter-rotating, are both cyclonic. This unique situation is not found elsewhere in the tropics. The generation of TCs by Sumatra wake vortices was first proposed many years ago by Kuettner $(1967,1989)$, although little attention has been given to it since.

To investigate the role of topographically induced vortices in TC formation over the IO, data from the 

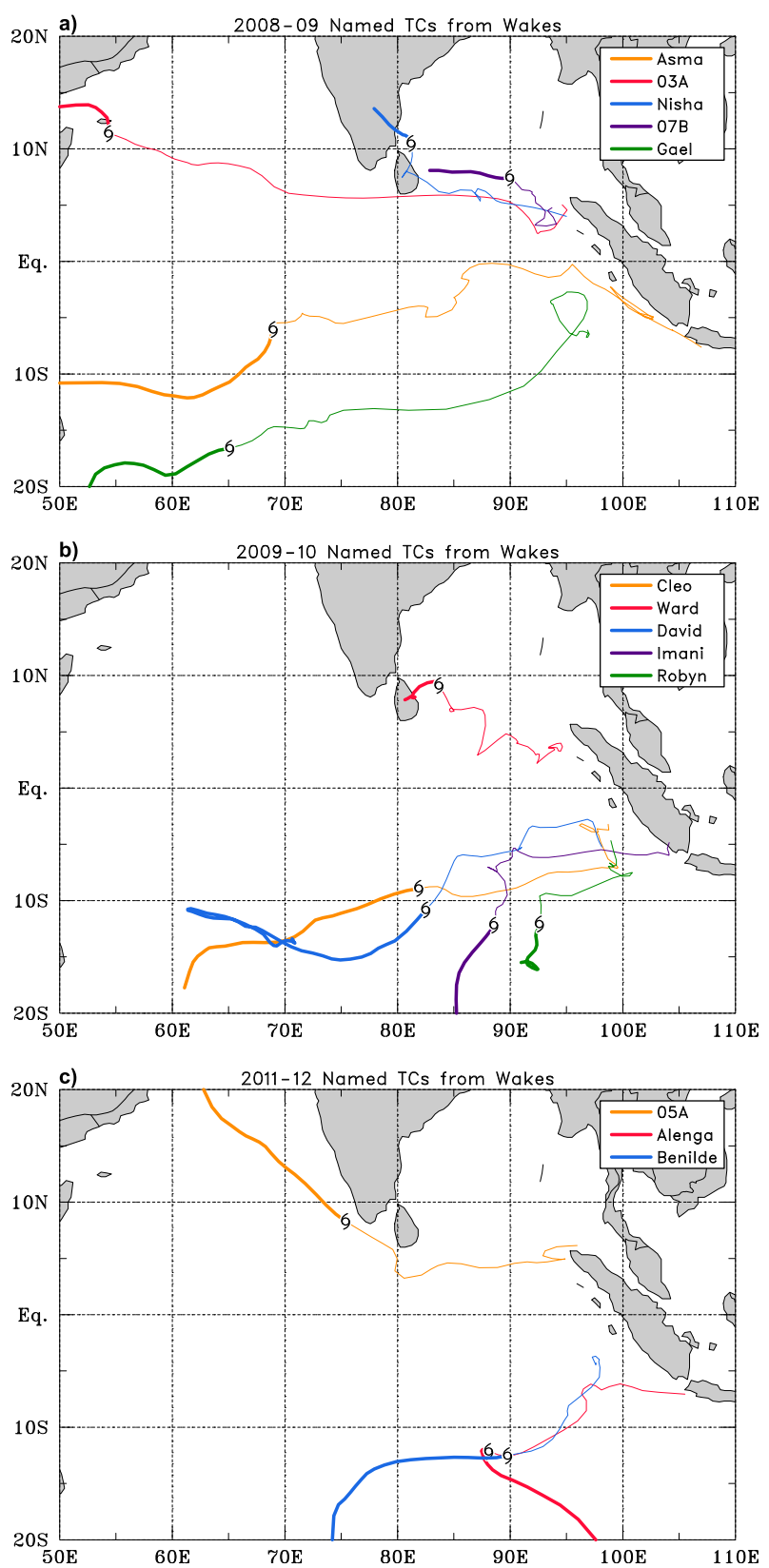

FIG. 14. Tracks of Indian Ocean tropical cyclones that originated from Sumatra region terrain-induced vortices during (a) May 2008-April 2009, (b) May 2009-April 2010, and (c) October 2011March 2012 time periods. Thin lines represent tracks of wake vortices before they developed into named TCs. Thick lines denote tracks of named TCs.

2008-10 Year of Tropical Convection (YOTC) and 2011-12 Dynamics of the MJO (DYNAMO) campaigns are used. ECMWF quarter-degree reanalysis and operational datasets from these campaigns have provided sufficient resolution to detect and track the wake vortices that were observed to develop at the northern and southern ends of Sumatra. The identification and tracking of vortices was carried out using the objective feature tracking code of Hodges $(1995,1999)$. In applying this algorithm to the Indian Ocean Basin, it was discovered that in addition to Sumatra, the Malay Peninsula and the mountains of west Java also contribute to cyclonic vortex development with eventual shedding of vortices into the Indian Ocean where they have the potential to influence TC genesis. Therefore, attention is focused on these two regions in addition to Sumatra itself with respect to topographic influence on the flow. The majority of the shed circulations from both northern and southern Sumatra regions occurred in easterly lowlevel flow, hence, were lee or wake vortices. However, some instances of blocking and splitting of low-level westerly equatorial flow by the mountainous island of Sumatra contributed to cyclonic circulations upstream of the island.

Key findings of this study are as follows:

1) Sumatra and the Malay Peninsula and west Java are prolific generators of low-level topographically induced circulations, contributing during YOTC and DYNAMO to 309 cyclonic circulations having an amplitude threshold of $1.0 \times 10^{-5} \mathrm{~s}^{-1}$ trackable over at least a 2 -day period. Of these, $33 \%$ were shed (i.e., moved downstream from their point of origination).

2) During the $2.5 \mathrm{yr}$ of the two campaigns, ${ }^{4} 13 \mathrm{TCs}(5 \mathrm{in}$ the Northern Hemisphere and 8 in the Southern Hemisphere) originated from shed vortices, representing $13 \%$ of all shed events. These 13 TCs constituted $25 \%$ of all the TCs occurring in the Indian Ocean Basin during the period of study, indicating the important role of topography in TC genesis in the region.

3) For shed vortices that eventually became TCs, the average length of time from vortex genesis to the naming of the storms was 10.1 days, indicating a relatively long gestation period for these TC precursor disturbances.

Though terrain-induced vortices occurred throughout much of the year, the occurrence of TC genesis was in most cases (10 out of 13) confined to the OctoberDecember period due to the low environmental vertical wind shear as the monsoon transitions from boreal

\footnotetext{
${ }^{4}$ While the YOTC and DYNAMO time span is limited to $2.5 \mathrm{yr}$, a comparison of TC frequencies during these field campaigns to those of a 30-yr (1985-2014) climatology reveals that TC activity during the YOTC-DYNAMO period was quite close to normal.
} 

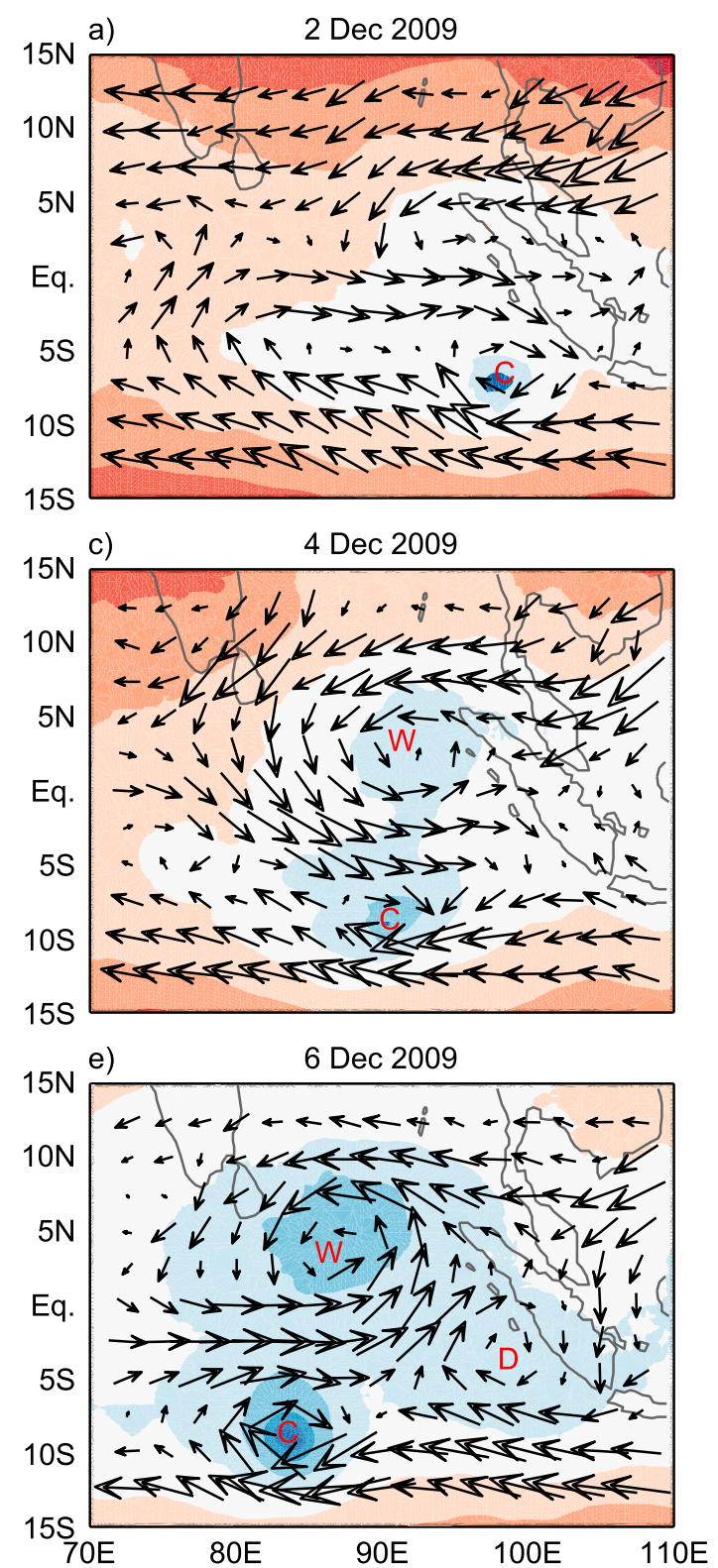

b)

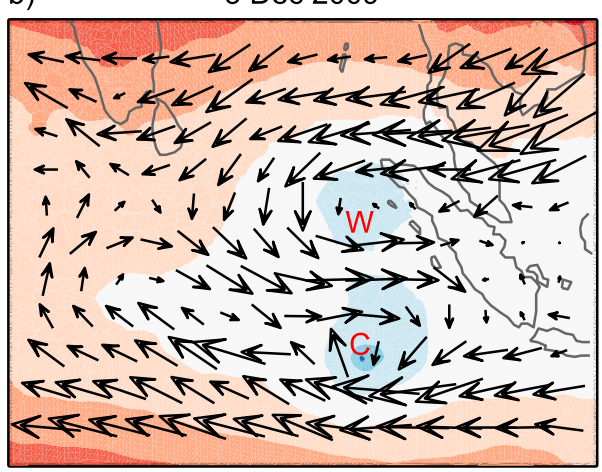

d)

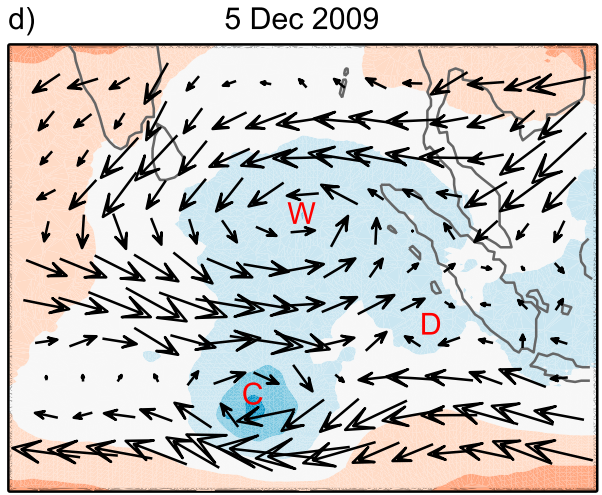

f)

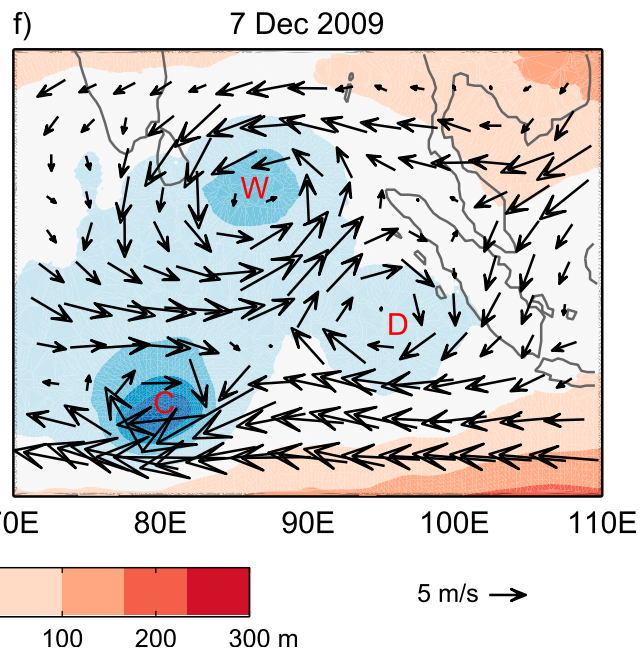

FIG. 15. The 850-hPa scaled wind vectors (see $5 \mathrm{~m} \mathrm{~s}^{-1}$ legend in lower right) and geopotential height anomalies (m, color scale at bottom) for (a) 2 Dec, (b) 3 Dec, (c) 4 Dec, (d) 5 Dec, (e) 6 Dec, and (f) 7 Dec 2009, showing the wake vortex precursors to TCs Cleo (C), Ward (W), and David (D). TCs Cleo, Ward, and David were officially named storms on 7,11, and $13 \mathrm{Dec}$, respectively. Geopotential height anomalies were calculated as the difference from a $10^{\circ} \mathrm{S}$ to $10^{\circ} \mathrm{N}$, Indian Ocean-wide $\left(35^{\circ}-120^{\circ} \mathrm{E}\right)$ geopotential height mean during OND of the same year.

summer to winter. The results are consistent with those of Kuettner (1989), who found that all but one twin TC case described in his study developed between October and December.

In four of the cases during YOTC and DYNAMO, easterly winds preceding the onset of the MJO's active phase encountered Sumatra, producing cyclonic wake vortices that formed and moved westward, subsequently interacting with the MJO convective envelope before developing into tropical storms. In the TC $05 \mathrm{~A}$ case that occurred during DYNAMO, both the MJO and equatorial waves (equatorial Rossby, mixed Rossby-gravity, 

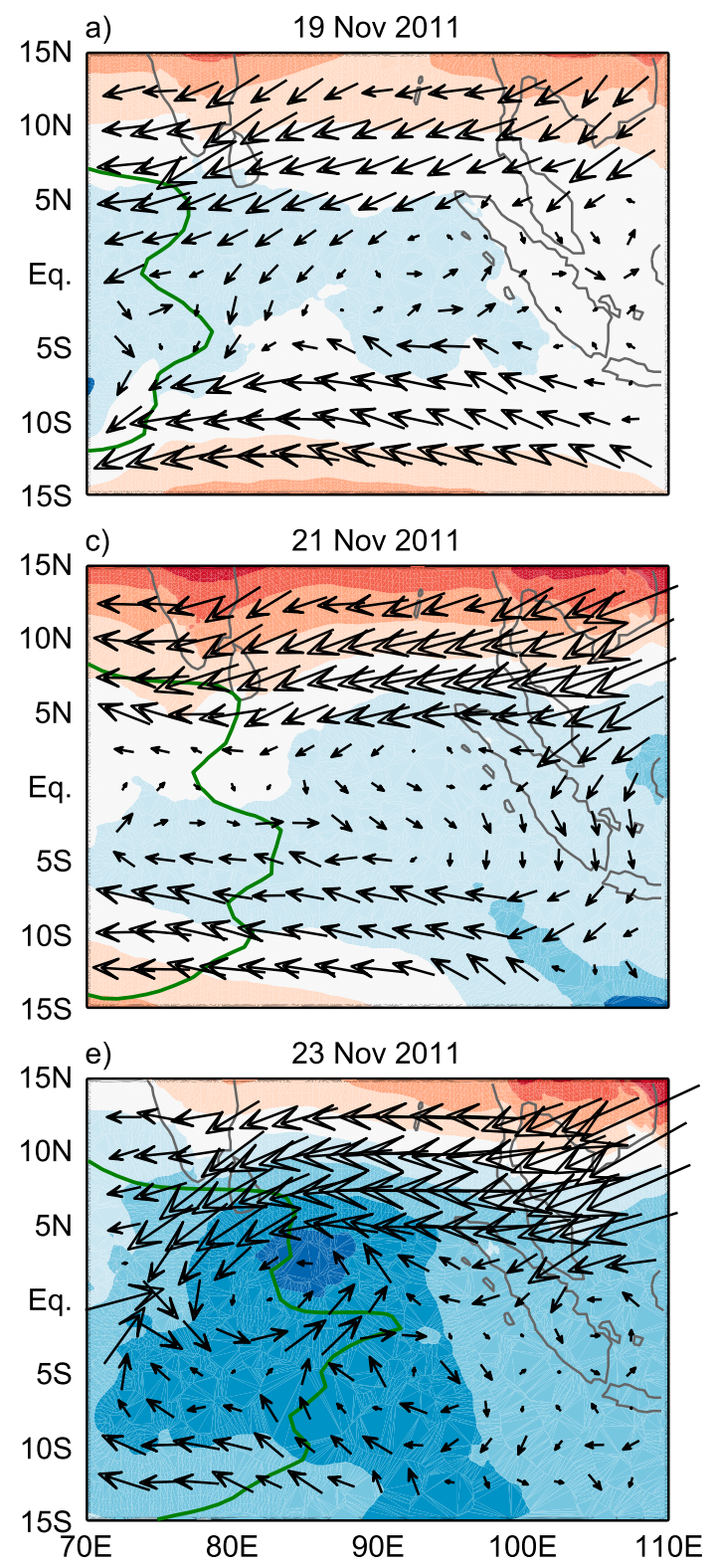

b)

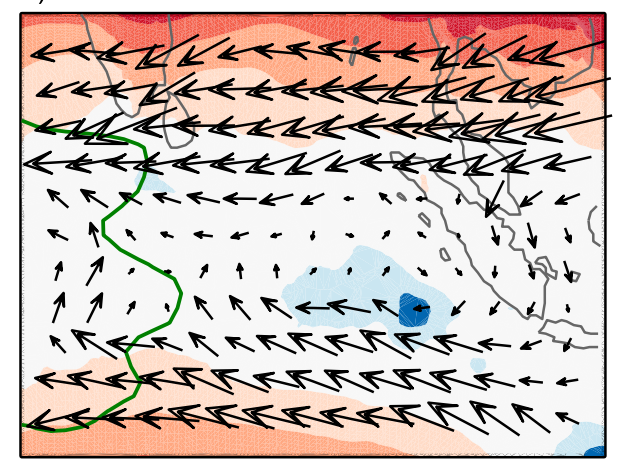

d)

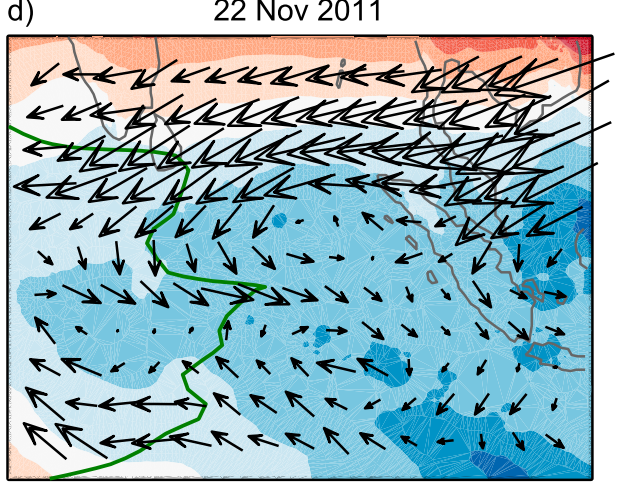

f)

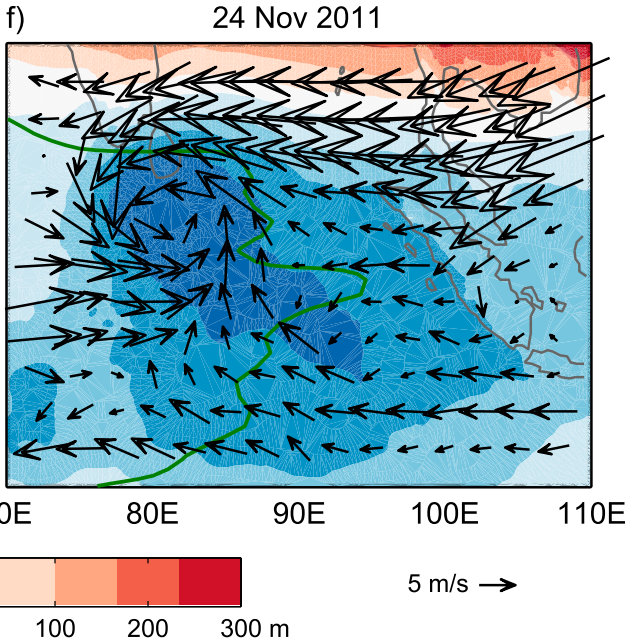

FIG. 16. As in Fig. 15, but for (a) 19 Nov, (b) 20 Nov, (c) 21 Nov, (d) 22 Nov, (e) 23 Nov, and (f) 24 Nov 2011, showing the wake vortex precursor to TC $05 \mathrm{~A}$, which was an officially named storm on 26 Nov 2011 . The dark green contour is $-10 \mathrm{~W} \mathrm{~m}^{-2} \mathrm{MJO}$-filtered OLR anomaly, indicating eastward progression of the MJO.

and Kelvin waves) appeared to contribute to the development of the TC (Gottschalck et al. 2013; Judt and Chen 2014; Oh et al. 2015), although these studies did not indicate the potential role of Sumatra wake vortices in providing the initial disturbance for the TC. Equatorial waves may have supported tropical cyclogenesis by producing low-level cyclonic vorticity and lowering vertical wind shear, as detailed in other studies (e.g., Frank and Roundy 2006), although the specifics of those processes have not been investigated here. In addition, Sumatra represents a unique situation of superposition of effects where Rossby gyres associated with convectively coupled Kelvin waves or the MJO can have their circulations enhanced when westerly equatorial flow is blocked upon encountering the island. 


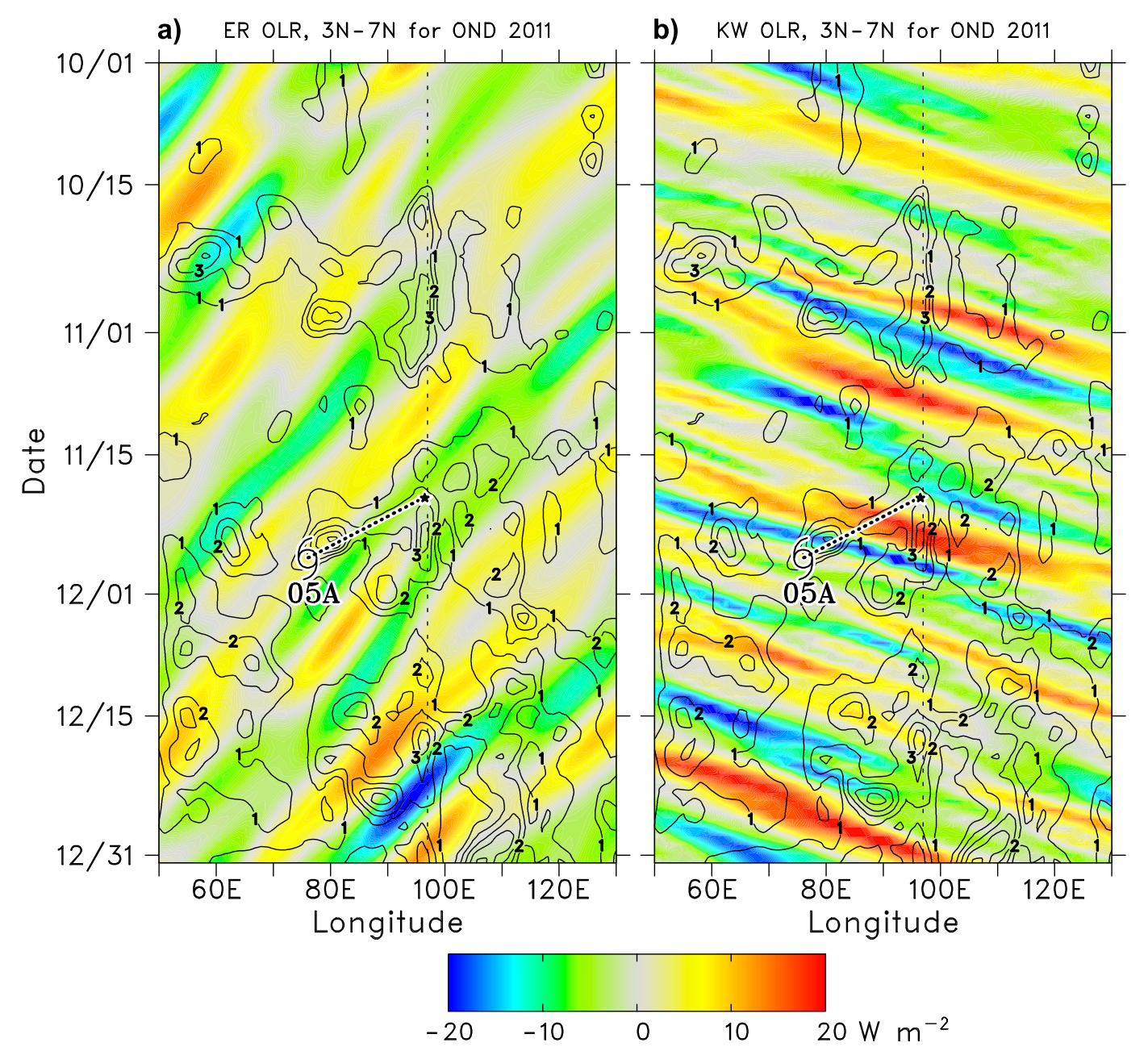

FIG. 17. Time-longitude diagrams of daily averaged relative vorticity (contours, plotted only for cyclonic vorticity starting at $1 \times 10^{-5} \mathrm{~s}^{-1}$ with a contour interval of $1 \times 10^{-5} \mathrm{~s}^{-1}$ ) and OLR anomalies (color, scale at bottom) filtered by (a) equatorial Rossby waves and (b) Kelvin waves for OND2011. Origins of vortices that later became TCs are indicated by stars, and longitudes and dates when vortices became named TCs are shown by a tropical cyclone symbol. Dotted lines point to the initial vortex from which the TC formed. Faint vertical dashed lines denote longitude of northern tip of Sumatra.

This study has provided further evidence for the idea first proposed by Kuettner $(1967,1989)$ that Sumatra may serve as a generator of wake vortices that subsequently develop into tropical cyclones. It has also been found, however, that the adjacent topography on the Malay Peninsula and west Java is an important contributor to terrain-induced vortices that move out over the Indian Ocean. Not all wake vortices develop into TCs, of course, since favorable environmental conditions are required for TC genesis to occur. The MJO and equatorial waves may provide those favorable conditions, though they are not a prerequisite for TC genesis. These observational findings from the YOTC and DYNAMO campaigns motivate more extensive climatological studies of this phenomenon as well as numerical simulations to further explore the mechanisms for this unique role of topography in TC genesis over the Indian Ocean.

Acknowledgments. We are indebted to Kevin Hodges of the University of Reading for providing his tracking code for our study and his assistance in setting it up for our application. We also thank Kathy Straub for providing the code for identifying convectively coupled equatorial wave modes. Comments and suggestions of two anonymous reviewers have led to significant improvements in the manuscript. The DYNAMO operational and YOTC reanalysis datasets were made available by the European Centre for Medium-Range Weather Forecasts. This work has been supported by National Science Foundation 
Grants AGS-1059899, AGS-1138353, and AGS-1360237, a 1-yr American Meteorological Society Fellowship awarded to Caitlin Fine, and the U.S. Navy.

\section{REFERENCES}

Aebischer, U., and C. Schär, 1998: Low-level potential vorticity and cyclogenesis to the lee of the Alps. J. Atmos. Sci., 55, 186-207, doi:10.1175/1520-0469(1998)055<0186:LLPVAC $>2.0 . C O ; 2$.

Bessafi, M., and M. C. Wheeler, 2006: Modulation of South Indian Ocean tropical cyclones by the Madden-Julian Oscillation and convectively coupled equatorial waves. Mon. Wea. Rev., 134, 638-656, doi:10.1175/MWR3087.1.

Duvel, J. P., 2015: Initiation and intensification of tropical depressions over the southern Indian Ocean: Influence of the MJO. Mon. Wea. Rev., 143, 2170-2191, doi:10.1175/MWR-D-14-00318.1.

Epifanio, C. C., 2003: Lee vortices. Encyclopedia of Atmospheric Sciences, J. R. Holton, J. Pyle, and J. A. Curry, Eds., Elsevier Science Ltd., 1150-1160.

——, and D. R. Durran, 2002: Lee-vortex formation in free-slip stratified flow over ridges. Part I: Comparison of inviscid theory and fully nonlinear viscous simulations. J. Atmos. Sci., 59, 1153-1165, doi:10.1175/1520-0469(2002)059<1153: LVFIFS $>2.0 . \mathrm{CO} ; 2$.

Etling, D., 1989: On atmospheric vortex streets in the wake of large islands. Meteor. Atmos. Phys., 41, 157-164, doi:10.1007/ BF01043134.

Farfán, L. M., and J. A. Zehnder, 1997: Orographic influence on the synoptic-scale circulations associated with the genesis of Hurricane Guillermo (1991). Mon. Wea. Rev., 125, 2683-2698, doi:10.1175/1520-0493(1997)125<2683:OIOTSS > 2.0.CO;2.

Frank, W. M., and P. E. Roundy, 2006: The role of tropical waves in tropical cyclogenesis. Mon. Wea. Rev., 134, 2397-2417, doi:10.1175/MWR3204.1.

Gottschalck, J., P. E. Roundy, C. J. Schreck III, A. Vintzileos, and C. Zhang, 2013: Large-scale atmospheric and oceanic conditions during the 2011-12 DYNAMO field campaign. Mon. Wea. Rev., 141, 4173-4196, doi:10.1175/MWR-D-13-00022.1.

Gray, W. M., 1968: Global view of the origin of tropical disturbances and storms. Mon. Wea. Rev., 96, 669-700, doi:10.1175/ 1520-0493(1968)096<0669:GVOTOO > 2.0.CO;2.

Hodges, K., 1995: Feature tracking on the unit sphere. Mon. Wea. Rev., 123, 3458-3465, doi:10.1175/1520-0493(1995)123<3458: FTOTUS $>2.0 . \mathrm{CO} ; 2$.

_ 1999: Adaptive constraints for feature tracking. Mon. Wea. Rev., 127, 1362-1373, doi:10.1175/1520-0493(1999)127<1362: ACFFT $>2.0 . \mathrm{CO} ; 2$.

Inness, P., and J. Slingo, 2006: The interaction of the Madden-Julian Oscillation with the Maritime Continent in a GCM. Quart. J. Roy. Meteor. Soc., 132, 1645-1667, doi:10.1256/qj.05.102.

Johnson, R. H., and P. E. Ciesielski, 2013: Structure and properties of Madden-Julian oscillations deduced from DYNAMO sounding arrays. J. Atmos. Sci., 70, 3157-3179, doi:10.1175/ JAS-D-13-065.1.

Judt, F., and S. S. Chen, 2014: An explosive convective cloud system and its environmental conditions in MJO initiation observed during DYNAMO. J. Geophys. Res. Atmos., 119, 2781-2795, doi:10.1002/2013JD021048.

Kerns, B., and S. S. Chen, 2014: Equatorial dry air intrusion and related synoptic variability in MJO initiation during DYNAMO. Mon. Wea. Rev., 142, 1326-1343, doi:10.1175/ MWR-D-13-00159.1.
Kuettner, J. P., 1967: The equatorial double vortex: Unique hydrodynamic role of Sumatra in atmospheric developments over the Indian Ocean. Bull. Amer. Meteor. Soc., 48, 637.

_ 1989: Easterly flow over the cross equatorial island of Sumatra and its role in the formation of cyclone pairs over the Indian Ocean. Wetter Leben, 41, 47-55.

Lee, H.-T., 2014: Outgoing longwave radiation (OLR)—Daily. NOAA's Climate Data Record (CDR) program, Climate Algorithm Theoretical Basis Document (C-ATBD), National Center for Atmospheric Research, Boulder, CO, $46 \mathrm{pp}$.

MacRitchie, K., and P. E. Roundy, 2012: Potential vorticity accumulation following atmospheric Kelvin waves in the active convective region of the MJO. J. Atmos. Sci., 69, 908-914, doi:10.1175/JAS-D-11-0231.1.

Madden, R. A., and P. R. Julian, 1971: Detection of a 40-50-day oscillation in the zonal wind in the tropical Pacific. J. Atmos Sci., 28, 702-708, doi:10.1175/1520-0469(1971)028<0702: DOADOI $>2.0$.CO;2.

$\longrightarrow$, and - 1972: Description of global-scale circulation cells in the tropics with a 40-50-day period. J. Atmos. Sci., 29, 1109-1123, doi:10.1175/1520-0469(1972)029<1109:DOGSCC >2.0.CO;2.

Moncrieff, M. W., D. E. Waliser, M. J. Miller, M. A. Shapiro, G. R. Asrar, and J. Caughey, 2012: Multiscale convective organization and the YOTC virtual global field campaign. Bull. Amer. Meteor. Soc., 93, 1171-1187, doi:10.1175/ BAMS-D-11-00233.1.

Mori, S., and Coauthors, 2004: Diurnal land-sea rainfall peak migration over Sumatera Island, Indonesian Maritime Continent, observed by TRMM satellite and intensive rawinsonde soundings. Mon. Wea. Rev., 132, 2021-2039, doi:10.1175/ 1520-0493(2004)132<2021:DLRPMO > 2.0.CO;2.

Oh, J.-H., X. Jiang, D. E. Waliser, M. W. Moncrieff, R. H. Johnson, and P. Ciesielski, 2015: A momentum budget analysis of westerly wind events associated with the Madden-Julian Oscillation during DYNAMO. J. Atmos. Sci., 72, 3780-3799, doi:10.1175/JAS-D-15-0044.1.

Qian, J.-H., 2008: Why precipitation is mostly concentrated over islands in the Maritime Continent. J. Atmos. Sci., 65, 14281441, doi:10.1175/2007JAS2422.1.

Ridout, J., and M. Flatau, 2011: Convectively coupled Kelvin wave propagation past Sumatra: A June case and corresponding composite analysis. J. Geophys. Res., 116, D07106, doi:10.1029/ 2010JD014981.

Rotunno, R., and P. K. Smolarkiewicz, 1991: Further results on lee vortices in low-Froude-number flow. J. Atmos. Sci., 48, 2204-2211, doi:10.1175/1520-0469(1991)048<2204:FROLVI>2.0.CO;2.

Roundy, P. E., 2008: Analysis of convectively coupled Kelvin waves in the Indian Ocean MJO. J. Atmos. Sci., 65, 1342-1359, doi:10.1175/2007JAS2345.1.

Schär, C., and R. B. Smith, 1993a: Shallow-water flow past isolated topography. Part I: Vorticity production and wake formation. J. Atmos. Sci., 50, 1373-1400, doi:10.1175/ 1520-0469(1993)050<1373:SWFPIT >2.0.CO;2.

$\ldots$, and —_, 1993b: Shallow-water flow past isolated topography. Part II: Transition to vortex shedding. J. Atmos. Sci., 50, 1401-1412, doi:10.1175/1520-0469(1993)050<1401: SWFPIT $>2.0 . \mathrm{CO} ; 2$.

Schreck, C. J., 2015: Kelvin waves and tropical cyclogenesis: A global survey. Mon. Wea. Rev., 143, 3996-4011, doi:10.1175/ MWR-D-15-0111.1.

_ and J. Molinari, 2009: A case study of an outbreak of twin tropical cyclones. Mon. Wea. Rev., 137, 863-875, doi:10.1175/ 2008MWR2541.1. 
, and _ 2011: Tropical cyclogenesis associated with Kelvin waves and the Madden-Julian oscillation. Mon. Wea. Rev., 139, 2723-2734, doi:10.1175/MWR-D-10-05060.1.

Serra, Y., G. Kiladis, and K. Hodges, 2010: Tracking and mean structure of easterly waves over the Intra-America seas. J. Climate, 23, 4823-4840, doi:10.1175/2010JCLI3223.1.

Smith, R. B., 1989: Hydrostatic flow over mountains. Advances in Geophysics, Vol. 31, Academic Press, 1-41, doi:10.1016/ S0065-2687(08)60052-7.

Smolarkiewicz, P. K., and R. Rotunno, 1989: Low Froude number flow past three-dimensional obstacles. Part I: Baroclinically generated lee vortices. J. Atmos. Sci., 46, 1154-1164, doi:10.1175/ 1520-0469(1989)046<1154:LFNFPT $>2.0 . C O ; 2$.

Tuyau, J., 2009: Pluies diluviennes: Les pompiers et la Special Mobile Force en état d'alert (Torrential rains: Fire fighters and Special Mobile Force on high alert.) La Sentinelle, 29 December 2009. [Available online at http://www.lexpress.mu/article/pluiesdiluviennes-les-pompiers-et-la-special-mobile-force-en-\% C3\% A9tat-d\%E2\%80\%99alerte/.]

Waliser, D. E., and Coauthors, 2012: The "Year" of Tropical Convection (May 2008-April 2010): Climate variability and weather highlights. Bull. Amer. Meteor. Soc., 93, 1189-1218, doi:10.1175/ 2011BAMS3095.1.
Wheeler, M., and G. N. Kiladis, 1999: Convectively coupled equatorial waves: Analysis of clouds and temperature in the wavenumber-frequency domain. J. Atmos. Sci., 56, 374-399, doi:10.1175/1520-0469(1999)056<0374: $\mathrm{CCEWAO}>2.0 . \mathrm{CO} ; 2$.

Wu, C.-H., and H.-H. Hsu, 2009: Topographic influence on the MJO in the Maritime Continent. J. Climate, 22, 5433-5448, doi:10.1175/2009JCLI2825.1.

Wu, P., M. Hara, J.-i. Hamada, M. D. Yamanaka, and F. Kimura, 2009: Why a large amount of rain falls over the sea in the vicinity of western Sumatra Island during nighttime. J. Appl. Meteor. Climatol., 48, 1345-1361, doi:10.1175/ 2009JAMC2052.1.

Yoneyama, K., C. Zhang, and C. N. Long, 2013: Tracking pulses of the Madden-Julian oscillation. Bull. Amer. Meteor. Soc., 94, 1871-1891, doi:10.1175/BAMS-D-12-00157.1.

Zehnder, J. A., D. M. Powell, and D. L. Ropp, 1999: The interaction of easterly waves, orography, and the intertropical convergence zone in the genesis of eastern Pacific tropical cyclones. Mon. Wea. Rev., 127, 1566-1585, doi:10.1175/ 1520-0493(1999)127<1566:TIOEWO>2.0.CO;2.

Zhang, C., 2005: Madden-Julian Oscillation. Rev. Geophys., 43, RG2003, doi:10.1029/2004RG000158. 